\title{
Mitochondrion-processed TERC regulates senescence without affecting telomerase activities
}

\author{
Qian Zheng ${ }^{1}$, Peipei Liu', Ge Gao', Jiapei Yuan', Pengfeng Wang ${ }^{2}$, Jinliang Huang', Leiming Xie', \\ Xinping Lu' ${ }^{1}$, Fan $\mathrm{Di}^{1}$, Tanjun Tong ${ }^{2,3}$, Jun $\mathrm{Chen}^{2,3}$, Zhi Lu' ${ }^{1}$, Jisong Guan ${ }^{1}$, Geng Wang ${ }^{1 凶}$ \\ ${ }^{1}$ MOE Key laboratory of Bioinformatics, Cell Biology and Development Center, School of Life Sciences, Tsinghua University, \\ Beijing 100084, China \\ 2 Peking University Research Center on Aging, Beijing 100191, China \\ ${ }^{3}$ Department of Biochemistry and Molecular Biology, Peking University Health Science Center, Beijing 100191, China \\ $\square$ Correspondence: wangengfuan@163.com (G. Wang) \\ Received October 28, 2018 Accepted January 15, 2019
}

\begin{abstract}
Mitochondrial dysfunctions play major roles in ageing. How mitochondrial stresses invoke downstream responses and how specificity of the signaling is achieved, however, remains unclear. We have previously discovered that the RNA component of Telomerase $T E R C$ is imported into mitochondria, processed to a shorter form TERC-53, and then exported back to the cytosol. Cytosolic TERC-53 levels respond to mitochondrial functions, but have no direct effect on these functions, suggesting that cytosolic TERC-53 functions downstream of mitochondria as a signal of mitochondrial functions. Here, we show that cytosolic TERC-53 plays a regulatory role on cellular senescence and is involved in cognition decline in 10 months old mice, independent of its telomerase function. Manipulation of cytosolic TERC-53 levels affects cellular senescence and cognition decline in 10 months old mouse hippocampi without affecting telomerase activity, and most importantly, affects cellular senescence in terc ${ }^{-1-}$ cells. These findings uncover a senescence-related regulatory pathway with a non-coding RNA as the signal in mammals.
\end{abstract}

Qian Zheng and Peipei Liu have contributed equally to this work.

Electronic supplementary material The online version of this article (https://doi.org/10.1007/s13238-019-0612-5) contains supplementary material, which is available to authorized users.
KEYWORDS mitochondria, retrograde signal, nucleus, transcription regulation, non-coding RNA, telomerase

\section{INTRODUCTION}

Human mitochondrial dysfunctions are linked to ageing related health problems such as metabolic defects, neurodegenerative diseases, and self-immune diseases (Bishop et al., 2010; Lopez-Otin et al., 2016; Sun et al., 2016). Mutations that affect mitochondrial bioenergetics and biosynthesis have been shown to modulate signaling pathways and gene expression through mitochondrial retrograde signaling (Wallace, 2012; Guha and Avadhani, 2013). The most well studied mitochondrial retrograde signals are calcium ion and ROS (Kotiadis et al., 2014; Sullivan and Chandel, 2014; Reczek and Chandel, 2015; Gottlieb and Bernstein, 2016). A decrease in calcium import into mitochondria increases cytosolic calcium concentration, which leads to transcriptional upregulation of over 100 genes including those involved in glucose metabolism, apoptosis and tumorigenesis (Kotiadis et al., 2014; Gottlieb and Bernstein, 2016). Mitochondrion-produced ROS initiate signaling in cellular processes such as proliferation, antioxidant gene regulation, apoptosis and aging through redox mechanism (Sullivan and Chandel, 2014; Reczek and Chandel, 2015). Both $\mathrm{Ca}^{2+}$ and ROS, however, lack specificity as signaling molecules. How mitochondria regulate a cellular process through retrograde signaling specifically remains relatively unexplored.

The roles mitochondria play during ageing are more complicated than originally expected. Mitochondrial 
dysfunctions contribute to different aspects of ageing including cellular senescence, decline of stem cell activity and inflammation (Sun et al., 2016). Mitochondrial impairments trigger mitochondrial unfolded protein responses and mitophagy that also have protective effects and in turn may extend longevity in model organisms such as C. elegans (Yee et al., 2014; Schulz and Haynes, 2015; Sun et al., 2016). These processes are regulated by a complex network of signaling pathways, and the intricate interplay and coregulation only start to unfold.

Mitochondria import a variety of cytosolic non-coding RNAs, including tRNAs, rRNAs, microRNAs and IncRNAs (Chang and Clayton, 1989; Alfonzo and Soll, 2009; Wang et al., 2010; Mercer et al., 2011; Zhang et al., 2014; Cheng et al., 2018). The import pathway is partially characterized in mammalian cells with PNPASE, a mitochondrial IMS (intermembrane space) protein, as an important regulator (Wang et al., 2010; Vedrenne et al., 2012; von Ameln et al., 2012; Sato et al., 2017). The mitochondrial functions of most imported RNAs, however, are unclear. We have previously discovered that the RNA component of Telomerase TERC is imported into mitochondria, processed to a shorter form TERC-53 by mitochondrial RNASET2, and then exported back to the cytosol (Cheng et al., 2018). Cytosolic TERC-53 levels respond to mitochondrial functions, but have no direct effect on these functions, suggesting that it could function as a mitochondrial retrograde signal (Cheng et al., 2018). Here, we show that cytosolic TERC-53 regulates cellular senescence and is involved in cognition decline in 10 months old mouse hippocampus without affecting telomerase activity or mitochondrial functions, possibly through regulating nuclear gene expression. These findings demonstrate that a noncoding RNA functions as a specific signaling molecule, a potential general mechanism, and provide a mechanism on how mitochondria regulates cellular senescence and possibly organismal ageing in mammals.

\section{RESULTS}

\section{TERC-53 regulates cellular senescence}

We have previously shown that the RNA component of Telomerase TERC is imported into mitochondria, processed to a shorter form TERC-53, and then exported back to the cytosol (Cheng et al., 2018). In the cells, TERC-53 is localized predominately in the cytosol. Cytosolic TERC-53 level responds to mitochondrial functions, but has no direct effect on these mitochondrial functions (Cheng et al., 2018). To investigate the function of cytosolic TERC-53, we stably overexpressed the RNA in 2BS (a primary strain of human embryonic lung fibroblast) cells with $\mathrm{H} 1$ promoter (Figs. 1A and S1A). Consistent with the previous results (Cheng et al., 2018), hTERC-53 overexpression led to a two fold increase of the cytosolic $h T E R C-53$ level, but had no effect on $h T E R C$ level (Fig. S1A). hTERC-53 overexpressing cells showed a significantly faster senescence rate (Figs. 1B and S1D). Full
Figure 1. hTERC-53 regulates cellular senescence. (A) Total RNA isolated from 2BS cell lines generated with the empty vector (con), or the vector expressing yeast CYC1 RNA (CYC1), full length hTERC (hTERC-full), hTERC-53 (hTERC-53) or hTERC-53r (hTERC-53r) were used as templates for RT-PCR with primers for CYC1, hTERC, TERC-53 (53), TERC-53r (53r) or GAPDH. (B) 2BS cells made with the empty vector (con), or the vector expressing yeast CYC1 RNA (CYC1), full length hTERC (hTERC-full) or hTERC-53 (hTERC-53) were grown to 37 PDs, and then stained for SA- $\beta$-gal. The bar graph shows the percentage of $S A-\beta-g a l$ positive cells. (C) 2BS cells made with the empty vector (con), or the vector expressing yeast CYC1 RNA (CYC1) or anti-sense hTERC-53 (hTERC-53r) were grown to 43 PDs and stained for SA- $\beta$-gal. (D) Immunoblots of the cell lysates with hTERC-53, hTERC-53r or CYC1 overexpression. (E) Immunoblots of MnSOD (MnSOD: Manganese Superoxide Dismutase) immunoprecipitation samples from cell lysates with $h T E R C-53$ or $h T E R C-53 r$ overexpression (Acetyl: acetylated MnSOD). (F) Northern blots of cytosolic hTERC, hTERC-53 and 5S rRNA in HEK cells $(\mathrm{H})$, and HEK cells overexpressing PNPASE $(P)$ with or without triptolide treatment $(2 \mu \mathrm{mol} / \mathrm{L}$ for $3 \mathrm{~h})$. (G) Immunoblots of HEK293 cells overexpressing PNPASE (PNP) or PNPASE with $h T E R C-53 r(P N P+53 r)$ (con: HEK cells harboring the empty vector). $(H)$ Quantification of the relative $p 16$ level in panel (G) $(n=3)$. (I) Percentage of SA- $\beta$-gal positive cells after $\mathrm{H}_{2} \mathrm{O}_{2}$ treatment and 3 days' recovery. Statistical comparisons are performed using unpaired $t$-tests; ${ }^{*} P<$ $0.05,{ }^{* *} P<0.01,{ }^{* \star *} P<0.001,{ }^{* * *} P<0.0001$. Data are presented as mean \pm standard error of the mean (s.e.m.).

length $h T E R C$ overexpressing cells also showed a similar phenotype, even though to a lesser extent (Fig. 1B), possibly the result of $h T E R C-53$ accumulation due to overexpression of the full length RNA (Fig. S1B). An impact on cellular senescence, however, could be the results of many factors and the $h T E R C-53$ effect could be indirect. To explore these alternatives, we constructed a stable cell line expressing anti-sense $h T E R C-53$ ( $h T E R C-53 r$ ). Expression of $h T E R C$ $53 r$ significantly reduced the cytosolic $h T E R C-53$ level, but had no effect on $h T E R C$ level (Fig. S1C), leading to a slowdown of the senescence rate (Figs. 1C and S1E).

Expression levels and modifications of cellular senescence markers were examined in the cells. An increase of p16 protein level was observed in $h T E R C-53$ overexpressing cells (Fig. 1D). Interestingly, the expression levels of many pro-longevity factors such as SIRT proteins were also upregulated and the inhibitory modification of MnSOD was removed in $h T E R C-53$ overexpressing cells, suggesting a compensatory response (Fig. 1D and 1E). Expression of $h T E R C-53 r$ led to minor downregulation of the expression levels of the senescence markers such as p-AMPK and p16, and removal of the inhibitory modification of MnSOD (Fig. 1D 


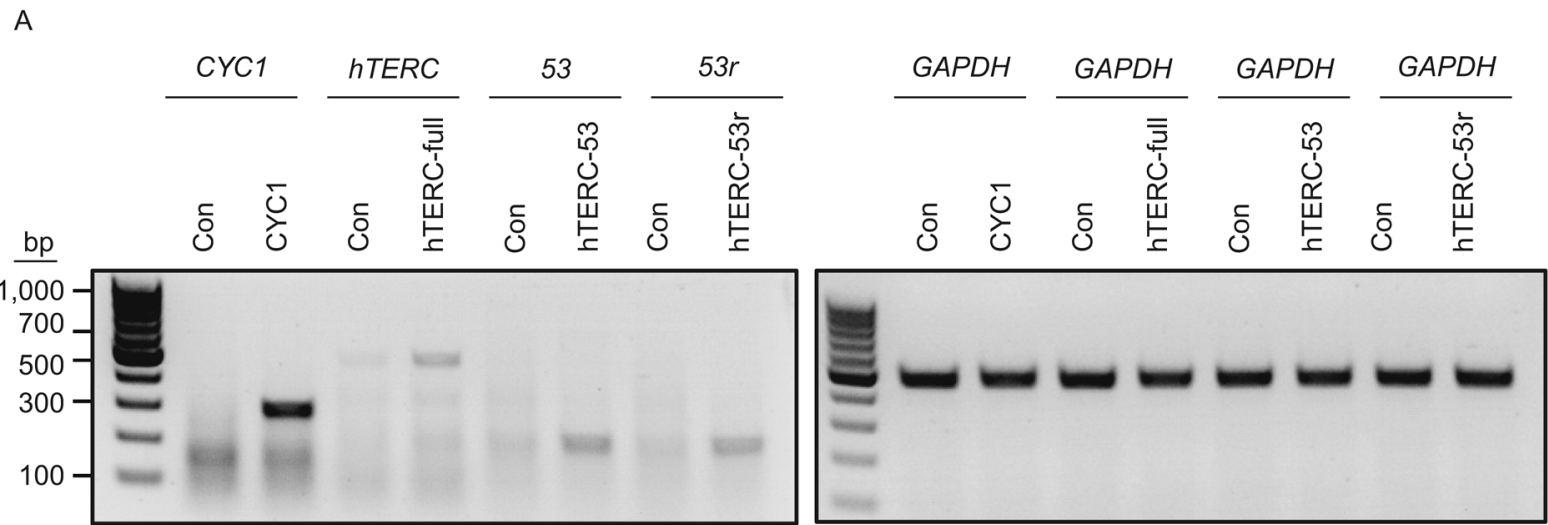

B

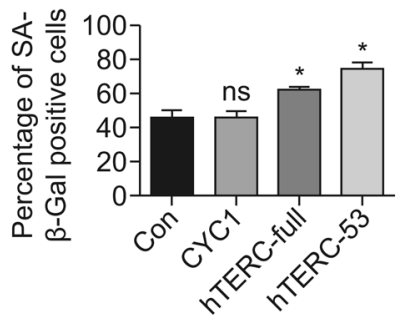

C

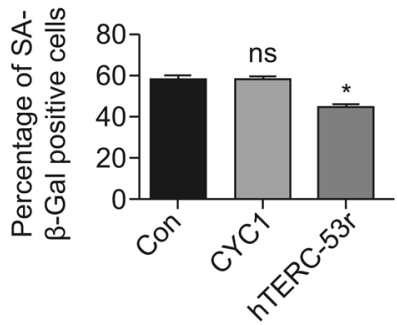

D

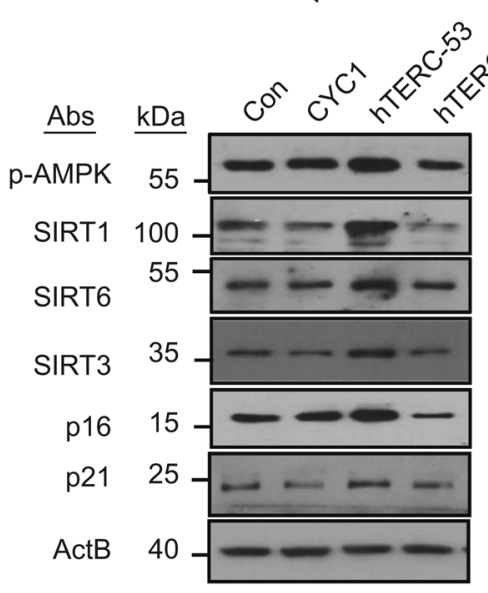

E

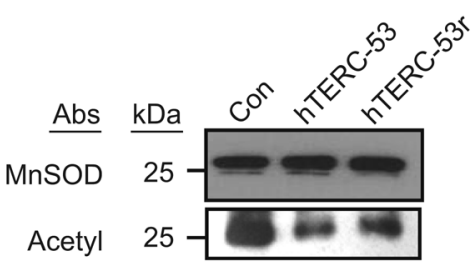

H
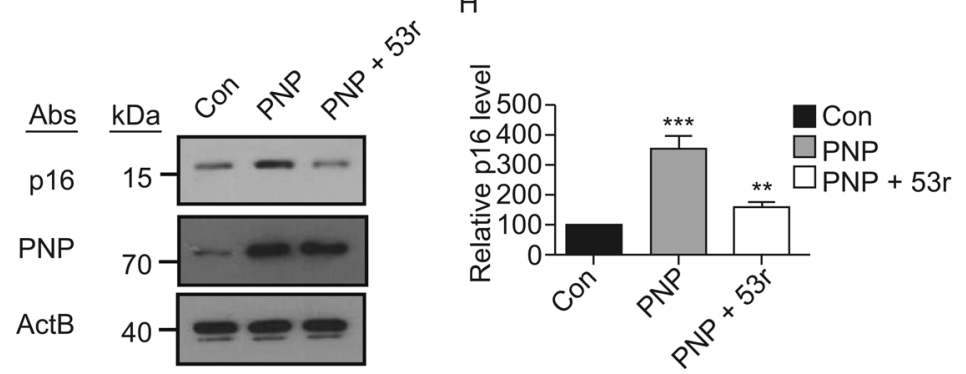

F
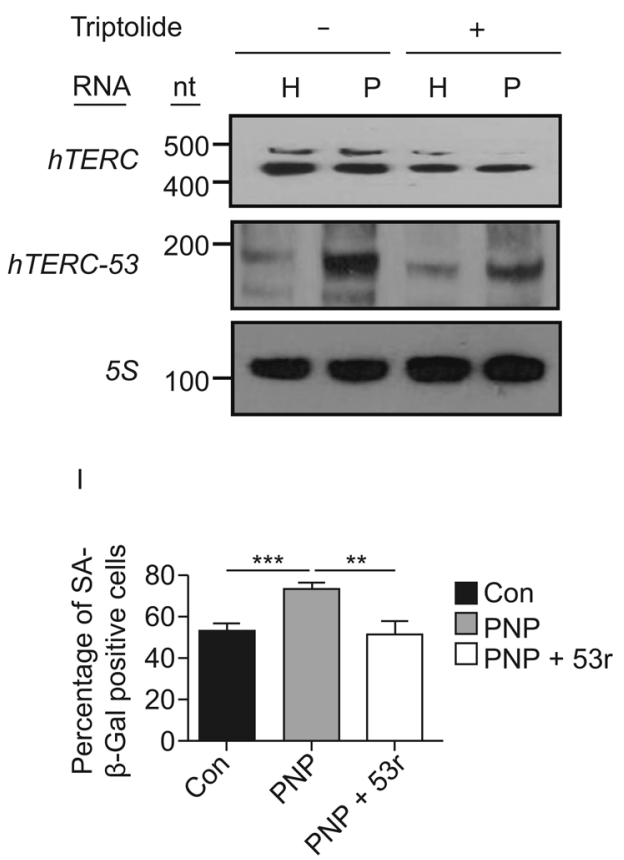
and $1 \mathrm{E})$. It remains to be elucidated how expression of $h T E R C-53$ and its antisense RNA could lead to the similar effect on MnSOD modification. However, overexpression and knockdown having similar effect is not uncommon with protein expressing genes (Phadke et al., 2011; Nicholls et al., 2012); it could also be the case with non-coding RNA regulation. These results also indicate that the role of TERC53 during cellular senescence is more regulatory than causative.

It has been shown previously that PNPASE overexpression exacerbates cellular senescence (Sarkar et al., 2003). PNPASE is involved in TERC trafficking into mitochondria where it is processed to TERC-53 by RNASET2, and PNPASE overexpression leads to an increase of cytosolic hTERC-53 level (Liu et al., 2017; Cheng et al., 2018). The increase of cytosolic $h T E R C-53$ level by PNPASE overexpression is not due to a drop in the RNA degradation rate, as cytosolic hTERC-53 showed a faster degradation rate in PNPASE overexpression cells (Fig. 1F). To examine whether cytosolic TERC-53 is involved in PNPASE's function in cellular senescence, $h T E R C-53 r$ was expressed in the PNPASE overexpressing cells. The increase of senescence rate and $\mathrm{p} 16$ level caused by PNPASE overexpression was mostly reversed by $h T E R C-53 r$ (Fig. 1G-I), further proving the involvement of TERC-53 in cellular senescence.

\section{TERC-53 functions independent of telomerase activity}

Since TERC is the essential RNA component of telomerase (Gall, 1990), we investigated whether TERC-53 functions by interfering with telomerase activity. The level, localization and activity of telomerase protein TERT were examined in hTERC-53 overexpressing and control cells. No significant difference of TERT level was observed in either the cytosol or the nucleus between $h T E R C-53$ overexpressing cells and the control cells (Fig. 2A and 2B). Cell lysates from 2BS cells expressing CYC1, hTERC-53r or overexpressing hTERC-53 all showed weak but similar level of telomerase activity (Fig. 2C and 2D). Telomere length was also examined in the 2BS cell lines, and no significant difference was observed (Fig. 2E).

To further examine whether TERC-53 functions by interfering with the functions of full length TERC, MEF cells were isolated from second generation terc $^{-/-}$embryos or control wild-type embryos, and infested with adenovirus for the expression of CYC1, mTerc, mTerc-53 or mTerc-53r. Consistent with the 2BS cell results, mTerc-53 overexpression accelerated wild-type MEF cell senescence and an increase of p16 protein level was observed in mTerc-53 overexpressing cells (Fig. 3A-D). mTerc-53r had only minor effect on the $m$ Terc-53 level (Fig. 3E), hence a lack of rescue effect on senescence. More importantly, mTerc-53 also accelerated senescence of terc $^{-1-}$ MEFs (Fig. 3A-D). No deceleration of senescence of terc ${ }^{-1-}$ MEFs by expression of $m$ Terc was observed, possibly due to the fact that $m T E R C$ deletion only has minor effect on cellular senescence in early
Figure 2. hTERC-53 expression does not have a clear effect on the level of telomerase protein TERT or telomerase activity. (A and B) TERT immunoblots of different fractions of HEK293 cells overexpressing $h T E R C$ 53 (53) or with the control vector (con). $\beta$-Tubulin was used as a loading control for total lysate and the cytosol and Creb for the nucleus. The graphs on the right (panel $(A)$ ) and the bottom (panel $(B)$ ) show the quantification of relative TERT levels. (C) Telomere-repeat amplification assay of telomerase activity in 2BS cells expressing yeast CYC1 RNA (CYC1) or anti-sense hTERC-53 (53r), overexpressing $h T E R C-53$ (53), or generated with the vector only (con). HEK293 (HEK) cell lysate was used as a positive control. 1× CHAPS lysis buffer was used as primer-dimer/PCR contamination control. TSR8 template was used as telomerase quantitation control. Heat-treated extracts were used as negative controls. (D) Quantification of the telomerase activity. (E) Comparison of the telomere length in 2BS cells expressing yeast CYC1 RNA (CYC1) or anti-sense hTERC-53 (53r), overexpressing hTERC-53 (53), or generated with the vector only (con). Statistical comparisons are performed using unpaired $t$-tests; ${ }^{*} P<$ $0.05,{ }^{* \star} P<0.01,{ }^{\star \star \star} P<0.001,{ }^{\star \star \star *} P<0.0001$. Data are presented as mean \pm standard error of the mean (s.e.m.).

generations (Blasco et al., 1997), and that introducing mTerc later in proliferation in the wild-type cells actually increased the level of $m$ Terc-53, hence the negative effect outweighing the positive effect. Telomere length was examined in the wild-type and terc $^{-1-}$ MEF cell lines. As expected, the telomeres in the terc $^{-1-}$ MEFs were shorter than the wild-type MEFs, but expression of CYC1, mTerc, mTerc-53 or mTerc$53 r$ in these second generation MEFs had no significant effect on telomere length (Fig. 3F). These results suggest that $\mathrm{mTerc-53}$ functions independent of full length mTerc and telomerase, and also provide an explanation for the lack of strong biological phenotypes in early generations of terc ${ }^{-/-}$ mice (Blasco et al., 1997; Rudolph et al., 1999; Jaskelioff et al., 2011), as deletion of $m T E R C$ also eliminates the generally pro-senescence $m$ Terc-53.

It has been shown previously that mitochondrion-localized RNASET2 is involved in TERC processing, and that overexpression of RNASET2 leads to an increase of cytosolic TERC-53 level (Cheng et al., 2018). With the involvement of TERC-53 in cellular senescence established, we examined whether RNASET2 has a similar effect on cellular senescence as TERC-53 does, by overexpressing or knocking down the protein in MEF cells (Fig. 3G-L). An acceleration of cellular senescence was observed with RNASET2 overexpression and a deceleration of senescence was observed with RNASET2 knockdown (Fig. 3G$\mathrm{L}$ ), consistent with a previous report that in human RNASET2 functions as a senescence inducing and tumor suppressor protein (Acquati et al., 2001), and providing a linkage between the processing and function of TERC-53. 
A
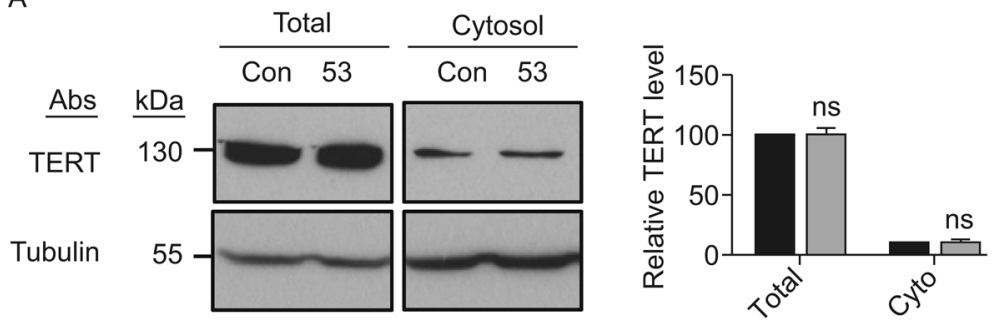

B

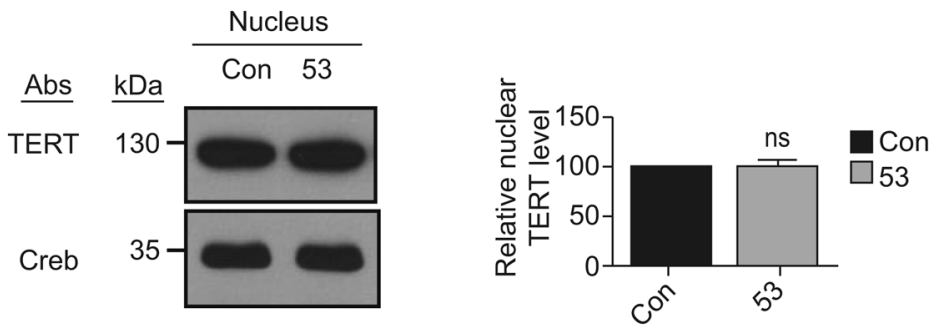

C
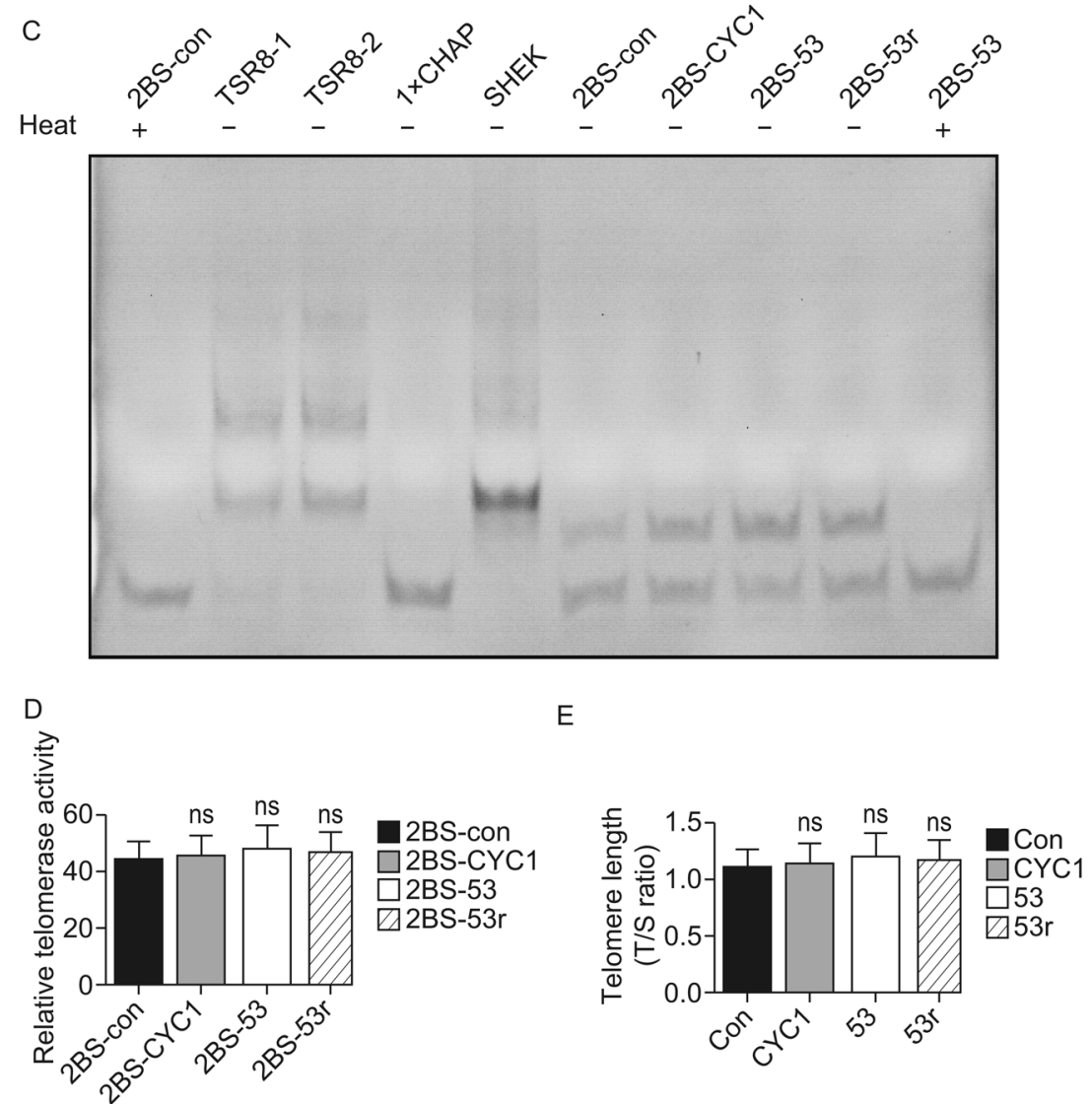

E

$\square 53$ 
$m$ Terc-53 is involved in cognition decline in 10 months old mouse hippocampus

We proceeded to study whether there is a physiological connection of the TERC-53 function. Cytosolic mTerc-53 was observed in all mouse tissues examined (Fig. S2A). In cultured neuronal N2a cells, mTerc-53 also localizes mainly in the cytosol and the level is significantly higher than in MEF TM6 cells (Fig. S2B-D). Moreover, N2a mitochondria import $m$ Terc more efficiently, even though PNPASE expression is not upregulated (Fig. S2E-G). Instead, higher TIM23 level was observed in N2a cells, suggesting a correlation between mitochondrial functional states and the processing and trafficking of mTerc (Fig. S2G and S2H). Next, the RNA level was examined in different age groups of mice. Majority of $m$ Terc-53 localizes in the cytosol of the brain cells, consistent with the results in the cultured cells (Fig. 4A). A significant increase of the cytosolic mTerc-53 level was observed in the brains as well as the livers of the 10 months old mice compared to the 4 months old; but in the 18 months old mice, the level drops again to that of the 4 months old (Fig. 4A-E), which seems consistent with the responses of cytosolic $h T E R C-53$ levels to different degrees of mitochondrial stresses (Cheng et al., 2018). The PNPASE level remains constant in all three groups, but an ageing-related mitochondrial protein BAP37 increases significantly in the 18 months old mice (Fig. S3A and S3B) (Coates et al., 1997), indicating changes of mitochondrial functional states as mice age. Transcription inhibitor triptolide treatment did not alter the pattern of $m$ Terc-53 levels in the three groups (Fig. S3C), suggesting no clear change of the degradation patterns of the RNAs during this ageing period. As expected, the telomere length in the brain showed no significant difference among the three age groups (Fig. S3D). Taken together, these data suggest that $m$ Terc- 53 may play a regulatory role in organismal ageing.

To further examine mTerc-53's physiological functions, we decided to use mouse hippocampus as a model and use adenoviral gene delivery, to avoid interference of telomerase activity during development and maturation (Fig. S4A). Contextual fear conditioning (CFC) (Fig. S5A) and spatial learning (Fig. S6A) were performed in separate cohorts. For CFC, mice (10 months old) were trained four weeks after adenovirus injection. Three groups exhibited comparable acquisition of contextual fear memory in single trial $24 \mathrm{~h}$ after training, but significantly higher percentage of freezing was observed in mTerc-53r group mice in 1-month recall compared to the control group and mTerc-53 group (Fig. 4F). No difference of the exploratory area and travel distance was observed among the three groups, suggesting no changes in mobility (Fig. S5B and S5C).

For spatial learning, mice were trained 8 weeks after injection. mTerc-53 group exhibited a slower learning curve to locate the hidden platform across 10 training days (Fig. S6A and S6B). The latency of mTerc-53 group to locate the platform in probe 1 was also significantly longer than the
Figure 3. $m$ Terc-53 accelerates senescence in both wild-type and terc ${ }^{-1-}$ MEF cells. (A) Wild-type MEF cells (WT) or terc $^{-1-}$ (KO) MEF cells were infected with adenovirus for expression of yeast CYC1 RNA (CYC1), full length mTerc (mTerc-full), mTerc-53 (mTerc-53) or mTerc$53 r$ (mTerc-53r), and stained for SA- $\beta$-gal on day 9. (B) Quantification of the $\beta$-gal positive cells in panel (A). 10 fields and about 500 cells were counted for each line. (C) Immunoblots of the MEF cell lysates with mTerc-53 or $m$ Terc-53r overexpression. (D) Quantification of the relative p16 level in panel (C) $(n=3)$. (E) Northern blots of cytosolic mTerc-53 in wild type MEFs with (mTerc-53r) or without (con) mTerc-53r overexpression. (F) Comparison of the telomere length in wild-type MEF cells (WT) or terc ${ }^{-1-}$ (KO) MEF cells infected with adenovirus for expression of yeast CYC1 RNA (CYC1), full length mTerc (mTerc-full), mTerc-53 (mTerc-53) or mTerc-53r (mTerc-53r). (G) Immunoblots of the MEF cell lysates with (con) or without RNASET2 overexpression. (H) SA- $\beta$-gal staining of MEF cells with (con) or without RNASET2 (T2) overexpression on day 9. (I) Quantification of the $\beta$-gal positive cells in panel (H). (J) Immunoblots of the MEF cell lysates with (con) or without RNASET2 knockdown. (K) SA- $\beta$-gal staining of MEF cells with (con) or without RNASET2 knockdown (KD) on day 14. (L) Quantification of the $\beta$-gal positive cells in panel (K). Statistical comparisons are performed using unpaired $t$ tests; ${ }^{\star} P<0.05,{ }^{* \star} P<0.01,{ }^{* * *} P<0.001,{ }^{* * *} P<0.0001$. Data are presented as mean \pm standard error of the mean (s. e.m.).

control group, suggesting a cognitive decline (Figs. 4G and S7). Each group preferred the Target quadrant to Left and Right quadrants, and the frequency of reaching the platform by each group was about equal, but the ratio of travel distance in quadrant $\mathrm{T}$ to that in quadrant $\mathrm{L}$ was significantly higher in mTer-53r group (Figs. 4H, S6C-E and S7). After three days' rest, the ratio of travel distance in quadrant $T$ to that in quadrant $L$ remained significantly higher in $m$ Ter $-53 r$ group and the frequency of reaching the platform by mTer53r group also appeared higher, suggesting a better retention of memory (Fig. 4I, 4J, S6C-E and S7). In summary, overexpression of mTerc-53r slowed down the cognitive decline in the 10 months mice, while mTerc-53 accelerated the decline of learning ability in the 10 months mice. The relatively milder effect of $m$ Terc- 53 could possibly be due to induction of the expression of $m$ Terc-53r in the hippocampus as a potential compensatory mechanism (Fig. S4B). No effect by mTerc-53 or mTerc-53r was observed in 18 months mice, indicating an early intervention is required (Fig. S6F).

$m$ Terc-53 affects cell proliferation and stem cell number in 10 months old hippocampi

To understand the role of TERC-53 in cognition decline in 10 months old hippocampi, immunohistochemistry was used to 
A

CYC1

mTerc-full

mTerc-53

mTerc-53r

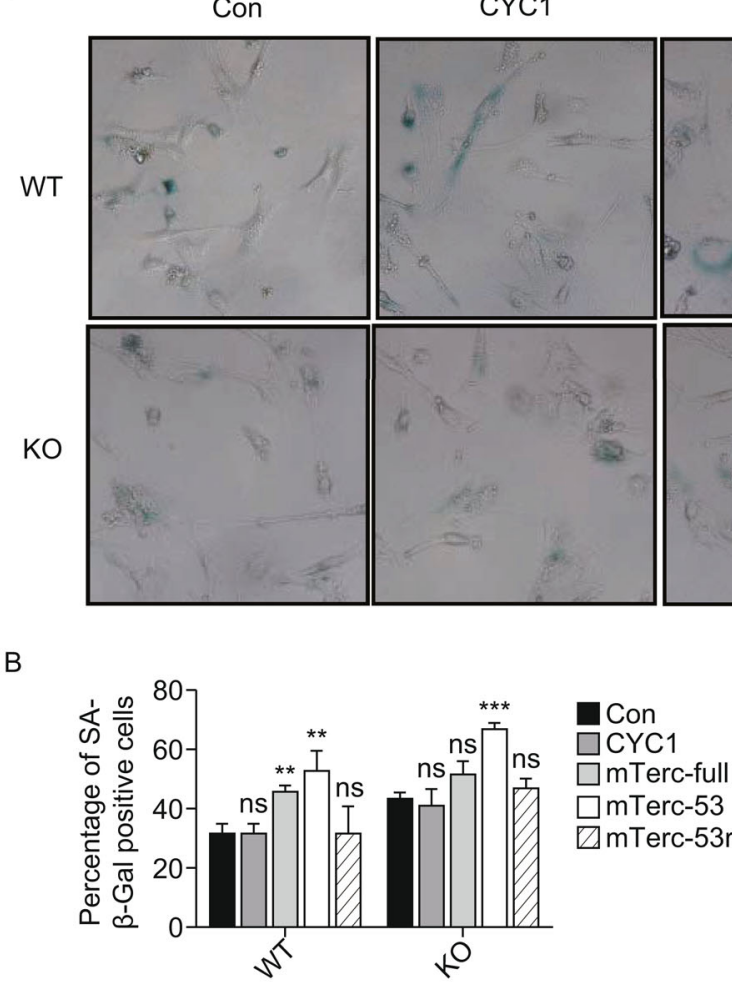

C
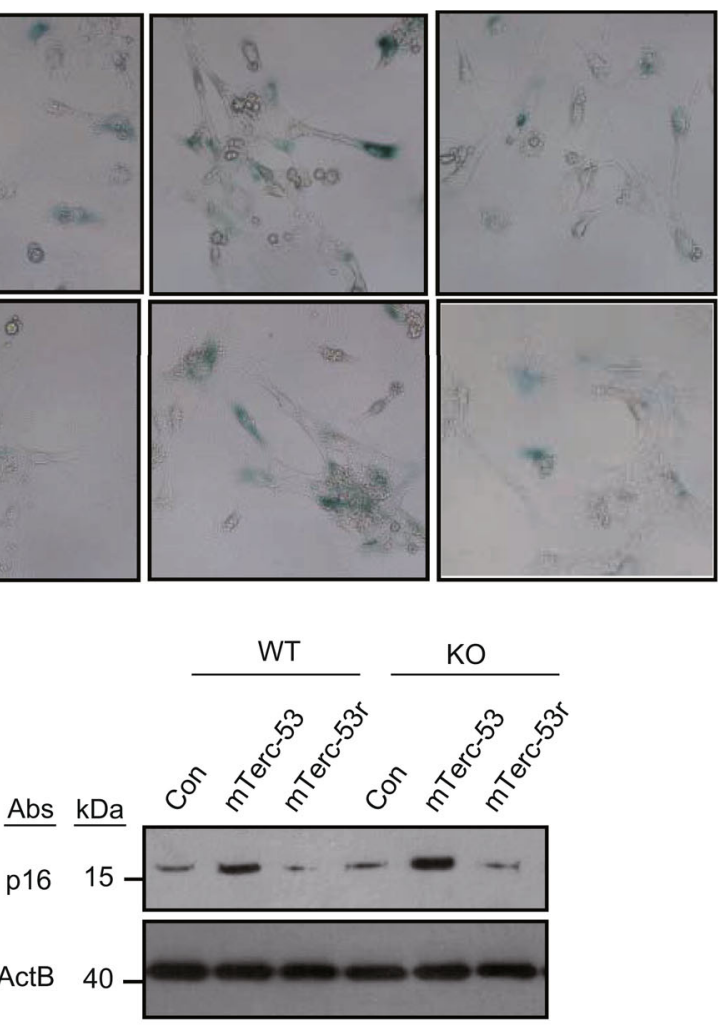

D

E

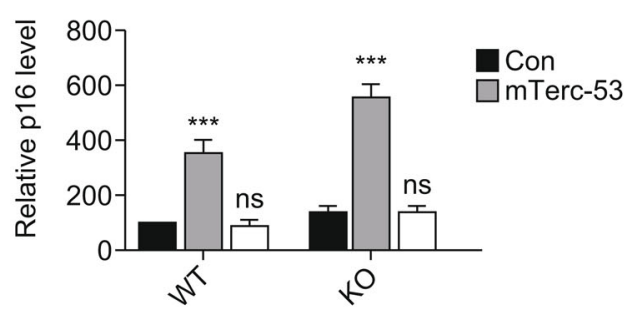

F

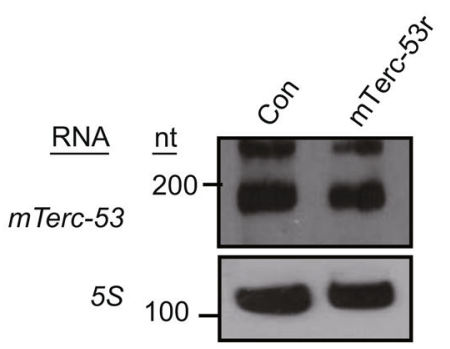

G

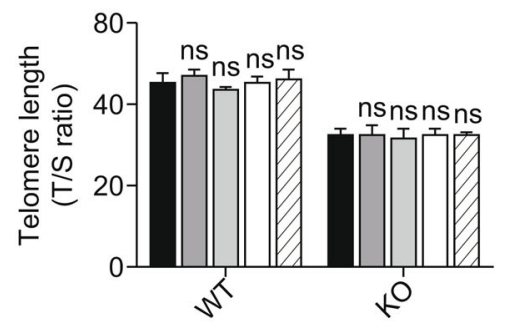

Con

$\square$ CYC1

$\square$ mTerc-full

$\square$ mTerc-53

$\square$ mTerc-53r

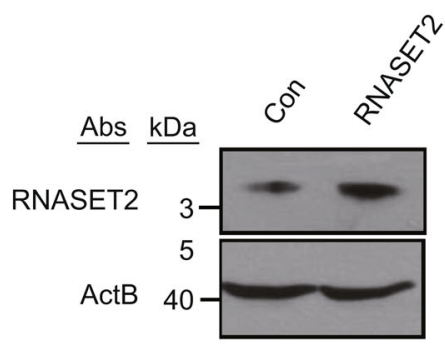


$\mathrm{H}$

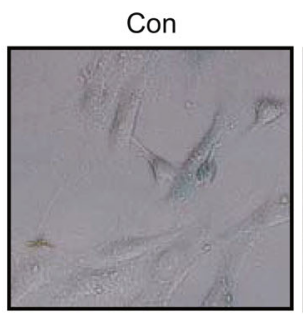

$J$

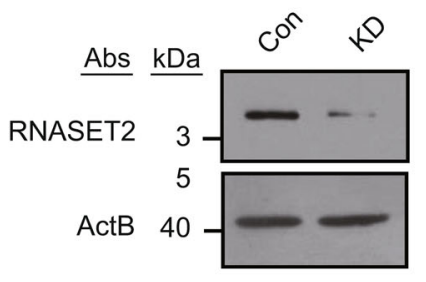

$\mathrm{T} 2$

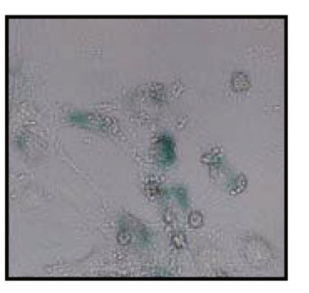

$\mathrm{K}$

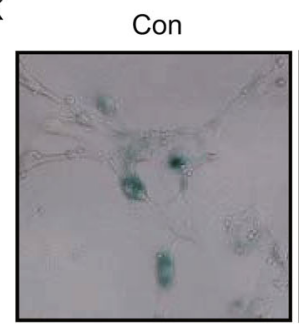

I

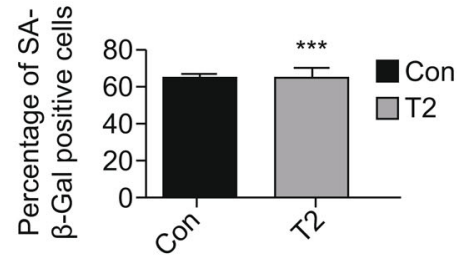

$\mathrm{L}$

Figure 3. continued.

evaluate the hippocampi of the mice overexpressing mTerc53 or $m T e r c-53 r$ and the control mice. Although no clear difference was observed with FOX3/NeuN (Neuron marker) staining, or $\mathbf{S} 100 \beta$ (Glial marker) staining, differences were observed in both BrdU incorporation (cell proliferation) and Nestin (stem cell marker) staining (Figs. 5 and S8). In hippocampi overexpressing $m T e r c-53$, both the total intensity of the signal and the number of the BrdU- and Nestin-positive spots decreased significantly, compared to the control hippocampi or those overexpressing mTerc-53r (Figs. 5 and S8), suggesting that a reduction of cell proliferation and exhaustion of stem cells could be the reason of cognition decline in the mTerc-53 overexpressing mice. No clear different was observed with COX/SDH (mitochondrial activity) labeling among the three groups, consistent with the previous finding that TERC-53 functions downstream of mitochondria and has little effect on mitochondrial functions (Cheng et al., 2018).

\section{Changes of TERC-53 level affect nuclear gene expression}

To gain more mechanistic insight into the function of TERC53, its effect on nuclear gene expression was examined. Total RNA were harvested from HEK293 cells overexpressing hTERC-53, hTERC53r or the control cells and analyzed using RNAseq. 87 differentially expressed protein coding genes with GFOLD $>1$ or $<-1$ were identified between $h T E R C-53$ overexpressing and control cells, and 1,950 differentially expressed protein coding genes were identified between $h T E R C-53 r$ overexpressing and control cells (Fig. 6A-D and Tables S1-4). qRT-PCR and RNAseq showed generally consistent changes (Fig. 6E). More importantly, qRT-PCR results of HEK293 RNA were also consistent with those of mouse hippocampus RNA (Fig. 6E and $6 \mathrm{~F}$ ). Gene ontology showed majority of differentially expressed genes were upregulated in TERC-53r overexpressing cells and mainly participate in several biological processes such as organelle organization, metabolism and neurogenesis, while the differentially expressed genes in TERC-53 overexpressing cells mainly participate in catabolic processes and stress responsive pathways, such as response to cold and calcium ion (Fig. $6 \mathrm{~B}$ and $6 \mathrm{D}$ ), suggesting that TERC-53 plays a regulatory instead of a causative role in senescence and ageing.

\section{TERC-53 regulates GAPDH nuclear translocalization}

TERC has been shown to interact with GAPDH in the nucleus, an important component of a gene transcriptosome, and nuclear translocalization is a key step for GAPDH to participate in the gene expression regulation (Sawa et al., 1997; Hara et al., 2005; Sen et al., 2008; Nicholls et al., 2012). Translocalization of GAPDH into the nucleus is induced by exposure of cells to environmental stressors such as starvation or treatment with Histone deacetylase inhibitor TSA (Trichostatin A), and plays an important role in DNA repair, autophagy and cell death (Chuang and Ishitani, 1996; Nagy et al., 2000; Azam et al., 2008; Chang et al., 2015). To examine whether TERC-53 could interact with the cytosolic pool of GAPDH and interfere with its nuclear translocalization or functions, GAPDH was purified and incubated with in vitro synthesized $h T E R C-53$. A specific binding of GAPDH to $h T E R C-53$ and $h T E R C$ but not control tRNA was observed (Fig. 7A and 7B). When TSA (Trichostatin $A$ ) was used to induce GAPDH nuclear translocation, in HEK 239 cells overexpressing hTERC-53, much less GAPDH signal was observed in the nucleus, compared to 
the control cells or the cells overexpressing $h T E R C-53 r$ (Fig. 7C and 7D). Interestingly, even without TSA treatment, GAPDH accumulated in the nucleus of the cells overexpressing $h T E R C-53 r$, suggesting that $h T E R C-53$ functions by interfering with the nuclear translocation of GAPDH, and subsequently affecting nuclear gene expression (Fig. 7C and 7D). It has been shown previously that GAPDH depletion accelerates cellular senescence of a cancer line (Phadke et al., 2011). To examine whether TERC-53 plays a role in the process, $h T E R C-53 r$ was expressed in the GAPDH knockdown cell line (Fig. 7E). As expected, GAPDH knockdown led to an increase of the senescence marker but depletion of $h T E R C-53$ by expression of the antisense RNA partially reversed the effect (Fig. 7F), suggesting interfering with GAPDH nuclear translocalization as a mechanism of TERC-53's function in cellular senescence.

\section{DISCUSSION}

Mitochondria import a variety of cytosolic RNAs, but the functions of the majority of these RNAs in mitochondria are unclear. We have previously shown that the RNA component of Telomerase is imported into mitochondria, processed to a shorter form TERC-53, and then exported back to the cytosol (Cheng et al., 2018). The cytosolic TERC-53 level acts as an indicator of mitochondrial functions, but has no direct effect on mitochondria (Cheng et al., 2018). Our results in this report show that cytosolic TERC-53 regulates cellular senescence and is involved in cognition decline in 10 months old mouse hippocampi through a telomerase independent mechanism. We also provide a possible mechanism on how cytosolic TERC-53 regulates nuclear gene expression. We have shown here a non-coding RNA functioning as a signaling molecule for regulation of nuclear gene expression, which appears to play a regulatory role in senescence.

Ageing in mammals is characterized by gradual loss of physiological functions. Mutations in mitochondrial DNA and mitochondrial dysfunctions have been established as one of the major factors in ageing (Lopez-Otin et al., 2013). Studies in mammals show an important correlation between nuclear gene expression and mitochondrial function changes during ageing (Lu et al., 2004; Bishop et al., 2010). How some mitochondrial dysfunction elicits certain nuclear gene expression change and how the specificity is achieved, however, is not clear. Our findings suggest that TERC-53 may function as a specific signaling molecule that bridges mitochondria and the nucleus. As the effect of mitochondrial dysfunctions on ageing is not simply causative, so is the effect of TERC-53. Modest reduction of mitochondrial function has been shown to activate a compensatory mechanism that increases stress resistance (Schulz and Haynes, 2015). Similarly, we have observed an induction of stress response pathways by TERC-53 overexpression. Cytosolic TERC-53 level responds differently to different levels of mitochondrial stress, it increased initially but then decreased as the stress increases. Similar changes were observed in mice as they age. These findings paint a complex picture of regulation networks during ageing in mammals. There is constant deterioration of the overall structures, as shown by accumulation of mutations in mitochondrial DNA and nuclear DNA, oxidation of the membranes, and so on; but there are also many coping mechanisms (Bishop et al., 2010). Noncoding RNAs may play a bigger role in ageing in mammals than expected.

One of the most important finding of this study is that mTerc-53 accelerates cellular senescence of second generation terc $^{-/-}$MEFs. TERC is the essential RNA component of telomerase, and the activity of telomerase plays a big role in cellular senescence (Gall, 1990; Bernardes de Jesus and Blasco, 2013). That exogenous expression of cytosolic TERC-53 has a similar impact on senescence of terc ${ }^{-/-}$cells as wild-type cells suggests TERC-53 does not function by interfering with telomerase activity. More importantly, it also provides an explanation for the lack of strong biological phenotypes in early generations of terc $^{-/-}$mice. Full length $m$ Terc, as an essential component of telomerase, has a prolongevity function, while its processed form mTerc-53 is generally pro-senescence. Deletion of mTerc essentially eliminates the pro-senescence mTerc-53. The effect of TERC-53 in cognition decline seems to be caused by its effect on cell proliferation, at least in mouse brains, which is consistent with its function on cellular senescence. Although we have evidence showing TERC-53 regulates nuclear gene expression and the nuclear translocation of GAPDH, a key component of a transcriptosome, the molecular mechanism of TERC-53's function in general and in cellular senescence remains to be fully elucidated.

\section{METHODS}

\section{Subcellular fractionation}

Mitochondria were isolated as previously described (Hachiya et al., 1993), except that mitoprep buffer $(0.225 \mathrm{~mol} / \mathrm{L}$ mannitol, $0.075 \mathrm{~mol} / \mathrm{L}$ sucrose and $20 \mathrm{mmol} / \mathrm{L}$ HEPES $\mathrm{pH}$ 7.4) was used as the homogenization buffer and wash buffer. For cytosol isolation, post mitochondrial supernatant was first spun at $21,000 \times g$ for $10 \mathrm{~min}$ at $4{ }^{\circ} \mathrm{C}$, and the supernatant was again spun at $100,000 \times \mathrm{g}$ for $30 \mathrm{~min}$ at $4{ }^{\circ} \mathrm{C}$. Nuclei and unbroken cells from mitochondrion isolation were pelleted at $800 \times g$ at $4{ }^{\circ} \mathrm{C}$. The pellet was resuspended in the mitoprep buffer, homogenized again on ice, and pelleted at $800 \times g$ at $4^{\circ} \mathrm{C}$. The last step was repeated twice, before the pellet was resuspended in lysis buffer (10 mmol/L HEPES pH 7.5, $10 \mathrm{mmol} / \mathrm{L} \mathrm{KCl,} 0.1 \mathrm{mmol} / \mathrm{L}$ EDTA, $1 \mathrm{mmol} / \mathrm{L}$ DTT, $0.5 \%$ Nonidet-40). The sample was kept on ice for $10 \mathrm{~min}$, and nuclei were pelleted at $12,000 \times \mathrm{g}$ for $10 \mathrm{~min}$ at $4{ }^{\circ} \mathrm{C}$

\section{Isolation of total and mitochondrial RNA}

$100 \mu \mathrm{g}$ Mitochondria were treated with digitonin $(90 \mu \mathrm{g} / \mathrm{mg}$ mitochondria) and $300 \mathrm{U}$ micrococcal nuclease (Thermo) in $200 \mu \mathrm{L}$ mitoprep buffer with $1 \mathrm{mmol} / \mathrm{L} \mathrm{CaCl}_{2}$ for $25 \mathrm{~min}$ at room temperature. The reaction was stopped by addition of $5 \mathrm{mmol} / \mathrm{L}$ EDTA. Mitochondria were collected and solubilized in $100 \mu \mathrm{L}$ SDS buffer 


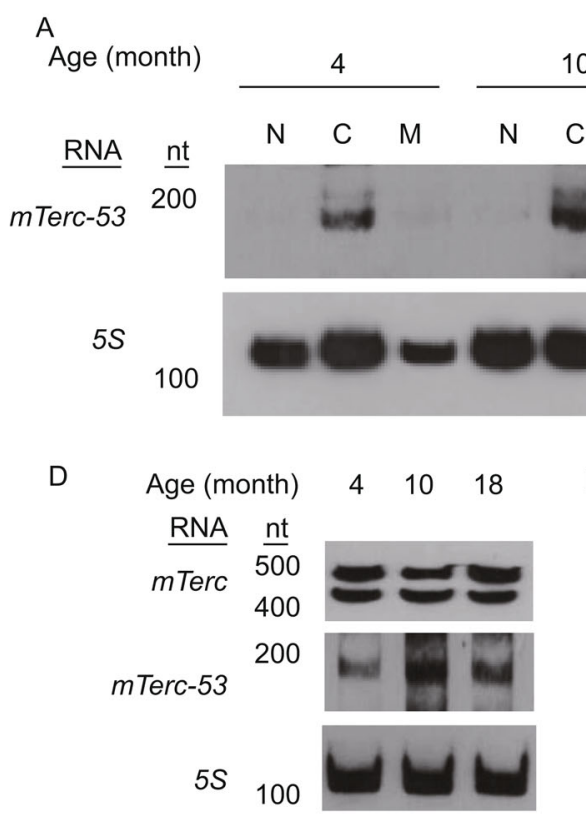

G

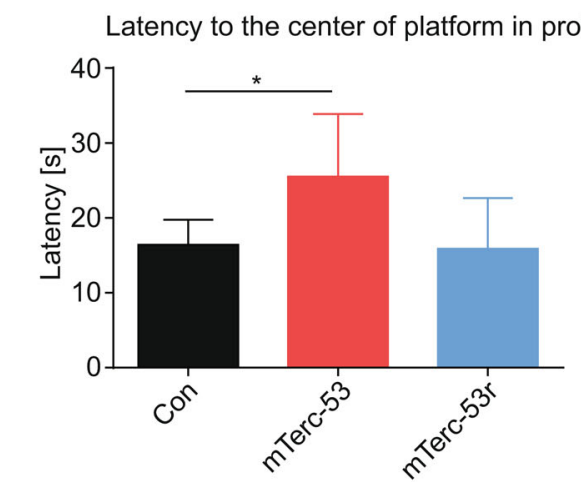

I

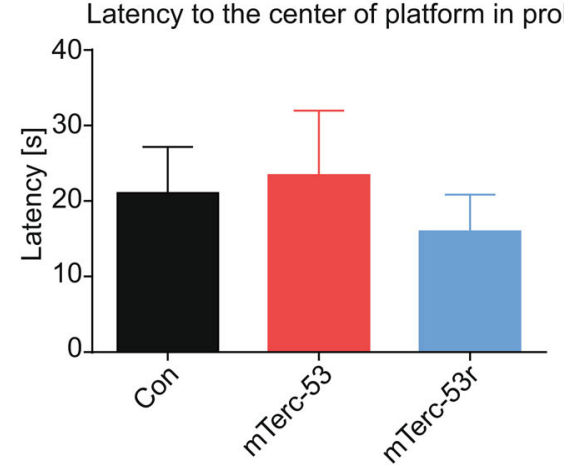

B

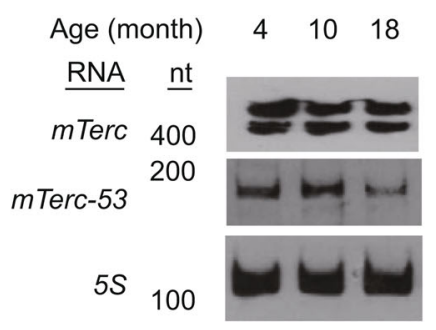

C
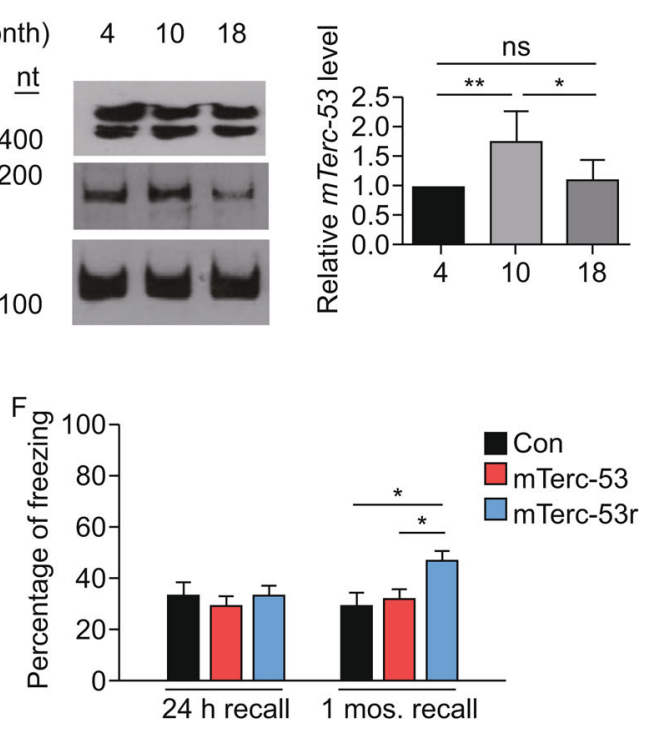
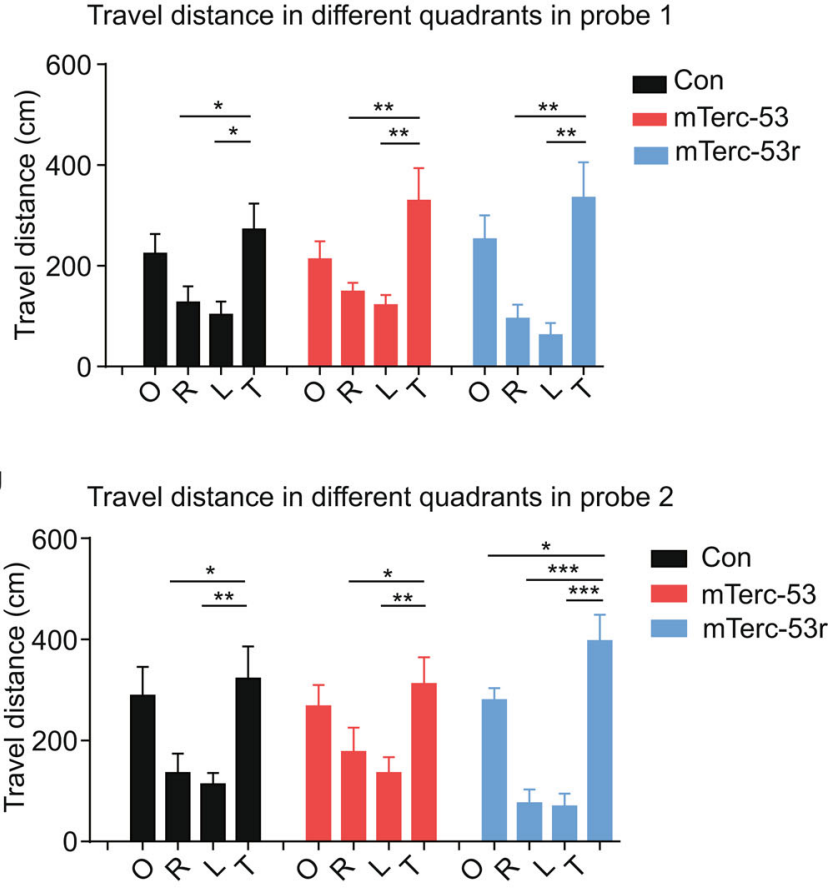

Figure 4. $m$ Terc-53 regulates cognition decline in ageing hippocampus. (A) Northern blots of $m$ Terc-53 in different cellular fractions ( $\mathrm{N}$ : nucleus, C: cytosol, M: mitochondria) isolated from the brains of 4 months old mice and those of 10 months old. (B) Northern blots of cytosolic mTerc-53 in the brains of 4 months, 10 months and 18 months old mice. (C) Relative cytosolic $m$ Terc-53 levels in the brains of the three groups of mice ( $n=8$ animals). (D) Northern blots of cytosolic $m$ Terc-53 in the livers of 4 months, 10 months and 18 months old mice. (E) Relative cytosolic mTerc-53 levels in the livers of the three groups of mice ( $n=8$ animals). (F) Contextual fear memory acquisition of control mice $(n=20)$ or mice overexpressing mTerc-53 $(n=20)$ or $m$ Terc- $53 r(n=20)$ in the hippocampus $24 \mathrm{~h}(24 \mathrm{~h}$ recall) or $1 \mathrm{month}(1 \mathrm{mos}$. recall) after training. (G-J) Morris water maze performance of control mice $(n=12)$ and mice overexpressing $m$ Terc-53 $(n=10)$ or $m$ Terc-53r $(n=10)$ in the hippocampus, Panel $(\mathrm{G})$ : latency in probe 1; Panel $(\mathrm{H})$ : travel distance in probe 1; Panel (I): latency in probe 2; Panel $(\mathrm{J})$ : travel distance in probe 2. O, R, L and T stand for Opposite, Right, Left and Target quadrant. The Statistical comparisons are performed using unpaired $t$-tests; ${ }^{*} P<0.05,{ }^{\star \star} P<0.01,{ }^{* \star \star} P<0.001,{ }^{* \star \star *} P<0.0001$. Data are presented as mean \pm standard error of the mean (s.e.m.). 
Figure 5. mTerc-53 regulates cell proliferation and stem cell number in ageing hippocampi. (A) Brdu incorporation assay on the three groups of mice. Upper panels are overlays of BrdU signals and DAPI signals. Bottom panels are BrdU images. (B) Quantification of the total BrdU signal in the hippocampus in panel (A). (C) The number of BrdU positive spots in the hippocampi of the three groups in panel (A). 24 slices were counted for each group $(n=$ 6). (D) Nestin (Stem cell marker) immunostaining of the hippocampi of the tree groups. Upper panels are overlays of Nestin signals and DAPI signals. Bottom panels are Nestin images. ( $E$ and F) Nestin (Stem cell marker) immunostaining of the hippocampi of the tree groups, Panel (E): total signal; Panel $(F)$ : number of foci. 24 slices were counted for each group. the Statistical comparisons are performed using unpaired $t$-tests; ${ }^{*} P<$ $0.05,{ }^{* *} P<0.01,{ }^{* * *} P<$ $0.001,{ }^{* * * *} P<0.0001$. Data are presented as mean \pm standard error of the mean (s.e.m.).

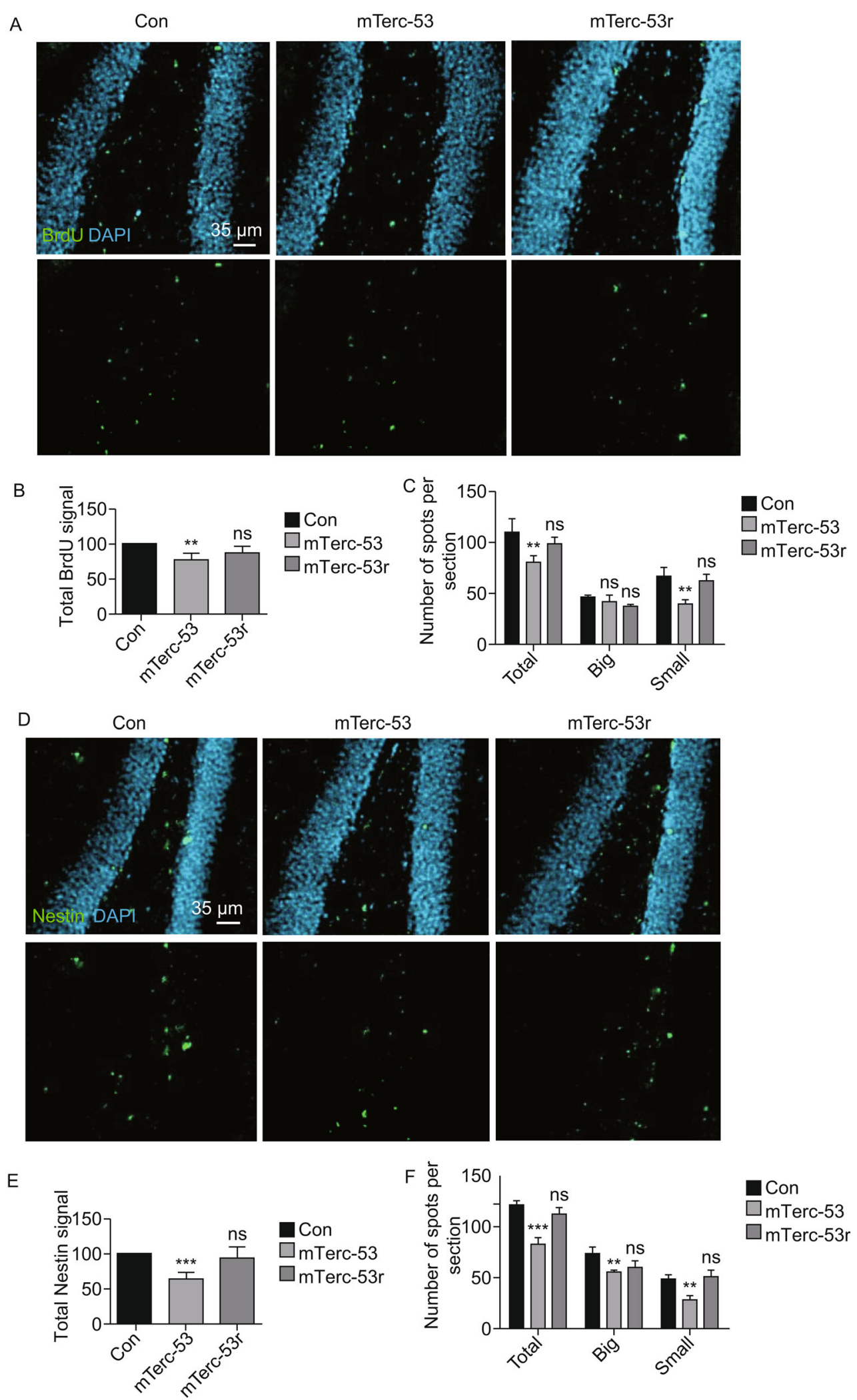


A

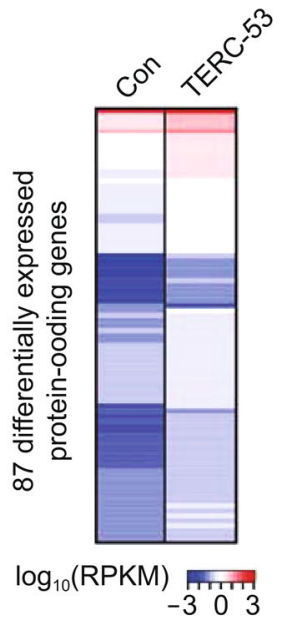

B

D

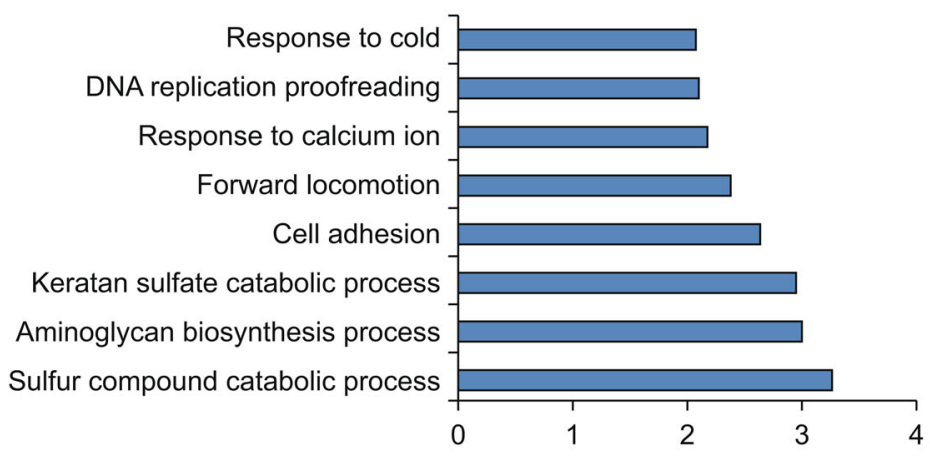

Regulation of signal transduction

Regulation of small GTPase medicated signal

Chromatin modification

Neurogenesis

Cell development

Regulation of gene expression

Transcription, DNA-templated

Organelle organization

Regulation of cellular metabolic process

Regulation of nitrogen compound metabolic..

Cytoskeleton organization

Regulation of nucleobase-containing compound..

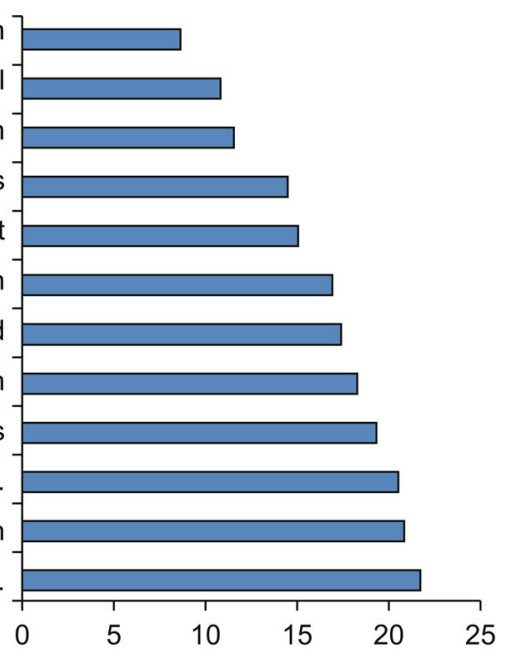

$\mathrm{F}$

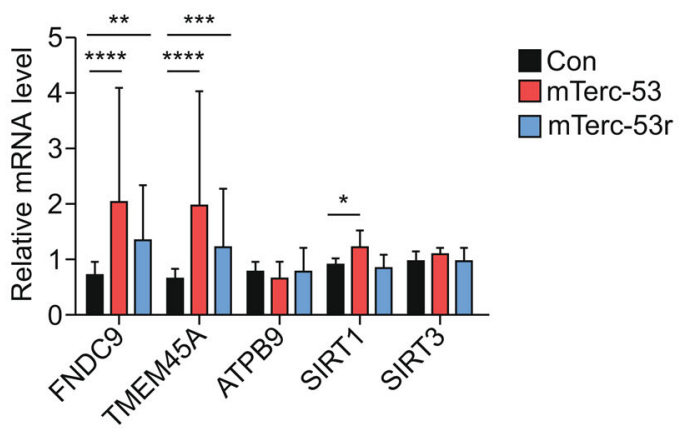

Figure 6. Exogenous expression of TERC-53 or TERC-53r affects nuclear gene expression. (A) Differentially expressed (DE) protein-coding genes between HEK cells overexpressing $h T E R C-53$ and the cells harboring the empty vector. (B) Gene ontology (GO) of the DE protein-coding genes between HEK cells overexpressing $h T E R C-53$ and the cells harboring the empty vector. (C) DE protein-coding genes between HEK cells overexpressing $h T E R C-53 r$ and the cells harboring the empty vector. (D) GO of the DE protein-coding genes between HEK cells overexpressing $h T E R C-53 r$ and the cells harboring the empty vector. (E) qRT-PCR of FNDC9, TMEM45A, ATPB9, SIRT1 and SIRT3 in control, $h T E R C-53$ or $h T E R C-53 r$ overexpressing HEK cells $(n=3)$. (F) qRT-PCR of FNDC9, TMEM45A, ATPB9, SIRT1 and SIRT3 in control, mTerc-53 or mTerc-53r overexpressing hippocampus (n = 8 for each group). Statistical comparisons are performed using unpaired $t$-tests; ${ }^{*} P<0.05,{ }^{* *} P<0.01,{ }^{* * *} P<0.001$, ${ }^{* * *} P<0.0001$. For mouse FNDC9 and TMEM45A qPCR results, F-test was used. Data are presented as mean \pm standard error of the mean (s.e.m.). 
(100 mmol/L NaCl, 1\% SDS, $20 \mathrm{mmol} / \mathrm{L}$ Tris $\mathrm{pH} 7.4$ ) with $10 \mu \mathrm{g} / \mathrm{mL}$ proteinase $\mathrm{K}$ and $5 \mathrm{mmol} / \mathrm{L}$ EDTA at $50{ }^{\circ} \mathrm{C}$ for $5 \mathrm{~min}$. RNA was purified using $400 \mu \mathrm{L}$ TRIzol reagent (Invitrogen), and treated with $500 \mathrm{U}$ RNase-free DNase I (Thermo) in $50 \mu \mathrm{L}$ buffer for $25 \mathrm{~min}$ at 37 ${ }^{\circ} \mathrm{C}$. DNase I was inactivated with the addition of $5 \mathrm{mmol} / \mathrm{L}$ EDTA and incubation at $70{ }^{\circ} \mathrm{C}$ for $10 \mathrm{~min}$. RNA was then purified with TRIzol. RNAseq samples and qRT-PCR samples were prepared the same way.

\section{RT-PCR}

RT-PCR was performed using the AccessQuick RT-PCR kit (Promega). For detection of hTERC, hTERC-111-f 5'-ACTTTCAGCGGGCGGAAAAGCCTCG-3' and hTERC-198-r 5'GCGAACGGGCCAGCAGCTGACATTT-3' were used as primers, and for detection of GAPDH, GAPDH-f 5'-GAGTACGTCGTGGAGTC-3' and GAPDH-r 5'-GGTCCACCACCCTGTTG-3' were used. For detection of COX2, cox2-f 5'-CGGCCGCACCGGTGCACATGCAGCGC-3' and cox2-r 5'-CGCGGATCCCTATGGTAAATACGGGC-3' were used. For detection of CYC1, cyc1-f $5^{\prime}$ ATGACTGAATTCAAGGCCGGTTCTG-3' and cyc1-247-r 5'TCAACCCACCAAAGGCCATC-3' were used. Phusion High-Fidelity DNA Polymerase was used for PCR of TERC and TERC-53.

\section{In vitro transcription}

RNA was synthesized using MEGAscript SP6 Kit (Ambion). For radiolabeled RNA synthesis, [ $\left.{ }^{32} \mathrm{P}\right]-\mathrm{UTP}$ was incorporated. For biotinlabeled RNA synthesis, biotin RNA labeling mix (Roche) was used. RNA was purified using TRIzol reagent.

\section{Plasmids}

To make the construct pQsuper-hTERC-53 for HEK293 transfection, full length $h T E R C$ was first RT-PCR amplified from HEK293 total RNA with the primer pair: (hTERC-f) 5'-GGGTTGCGGAGGGTGGG$3^{\prime}$ and (hTERC-r) 5'-GCATGTGTGAGCCGAGTCCT-3'. hTERC-53 was then PCR amplified from full length $h T E R C$ with the primer pair: (Bgl2-hTERC-53-f) 5'-GAAGATCTTAACTGAGAAGGGCGTAG-3' and (Xhol1-hTERC-247-r) 5'-CCGCTCGAGTGCGGGGTTCG GGGGCT-3'. The PCR product was digested with Bg/ll and Xhol, and inserted into pQsuper vector. The pQsuper-hTERC-53r antisense construct and pQsuper-hTERC $\triangle 1-63$ were generated with the same method using the primer pair: 5'-CCGCTCGAGTAACTGAGAAGGGCGTAG-3' and 5'-GAAGATCTTGCGGGGTTCGGGG GCT-3' and the primer pair: 5'-GAAGATCTGGCGTAGGCGCCGTG$3^{\prime}$ and 5'-CCGCTCGAGGCATGTGTGAGCCGAGTCCT-3'. For 2BS cell transfection, pMSCV-hH1 vector was made. $h H 1$ promoter fragment was cut from $\mathrm{pQsuper}$ vector with $\mathrm{BamHI}$ and $\mathrm{Xholl}$ and inserted into pMSCV-puro vector digested with Bg/ll and Xholl to generate pMSCV-hH1. To make the construct pMSCV-hH1-cyc1, $h H 1-C Y C 1$ fragment was cut from pQsuper-cyc1 and inserted into pMSCV-puro vector. With the same method, pMSCV-hH1-hTERCfull, pMSCV-hH1-hTERC-53 and pMSCV-hH1-hTERC-53r were also constructed. For mouse cell transfection, mTERC, mTERC-53, mTERC53r were PCR amplified using primers: 5'-GAAGATCTACCTAACCCTGATTTTCATTAGCTGTGG-3' and 5'-CCGC TCGAGGGTTGTGAGAACCGAGTTCC-3'; 5'-GAAGATCTAGCTC
CAGGTTCGCCGGGA-3' and 5'-CCGCTCGAGGTCCTCGCG GCGCTCGC-3'; 5'-GAAGATCTGTCCTCGCGGCGCTCGC-3' and 5'-CCGCTCGAGAGCTCCAGGTTCGCCGGGA-3'. The PCR products were digested with $B g / l$ and $X h o l$, and inserted into pQsuper vector. For bacterial expression of GAPDH, Pet28a-GAPDH-flag-his was generated using primers: 5'-CGCGGATCCATGGGGAAGGTGAAG-3' and 5'-CCGCTCGAGCTCCTTGGAGGCCATG-3', and BamHI and Xhol insertion. For colocalization study, PQCXIPGAPDH-mCherry was generated using primers 5'-AAAACCGGTATGGGGAAGGTGAAG-3' and 5'-CGCGGATCCACTCCTTGGAGGCCATG-3', and Agel and BamHI insertion.

\section{Cell culture and transfection}

HEK293 cells, TM6 cells (Wang et al., 2010), 2BS cells (Li et al., 2011), MEF cells and N2a cells were cultured in DMEM supplemented with $10 \%$ fetal bovine serum. All cell lines used were tested for mycoplasma contamination. To generate HEK293 stable cell lines, HEK293T cells were transfected with VSVg and Hit60 packaging vectors and the vector of interest using TurboFect (Thermo). Harvested retroviruses were used to infect HEK293 cells, followed by selection with $5 \mu \mathrm{g} / \mathrm{mL}$ puromycin. To generate 2BS stable cell lines, phoenix cells were transfected with the vector of interest using $\mathrm{CaCl}_{2}$ transfection protocol. Harvested retroviruses were used to infect 2BS cells at 20 PDs, followed by selection with $0.5 \mu \mathrm{g} / \mathrm{mL}$ puromycin. RNASET2 overexpression and knockdown was performed as previously described (Liu et al., 2017).

\section{Western blot}

Cells were washed twice in $1 \times \mathrm{PBS}, \mathrm{pH} 7.4$, and lysed in buffer $\mathrm{A}$ (10 $\mathrm{mmol} / \mathrm{L}$ HEPES, $\mathrm{pH} 7.9,10 \mathrm{mmol} / \mathrm{L} \mathrm{KCl}, 1.5 \mathrm{mmol} / \mathrm{L} \mathrm{MgCl}_{2}$ and $0.5 \% \mathrm{NP}-40$ ). Mitochondria were lysed directly in $1 \times$ SDS loading buffer. Protein lysates $(50 \mu \mathrm{g})$ were resolved by SDS-PAGE, transferred to nitrocellulose membranes, incubated for $1 \mathrm{~h}$ with $5 \%$ milk TBS-T and overnight with primary antibodies in $5 \%$ BSA at $4{ }^{\circ} \mathrm{C}$ or for $1-2 \mathrm{~h}$ at room temperature. Antibodies included anti-PNPASE $(1: 5,000)$ (Chen et al., 2006), anti-TIM23 (1:1000) (Abgent), antiMortalin (1:10,000) (Sigma-Aldrich), anti-Creb (1:1000) (Abcam), anti-ActB $(1: 2,000)$ (ABClonal), anti-Acetylated lysine (1:1000) (Cell Signaling Technology), anti-TERT (1:1000) (Abcam), anti-p-AMPK (Thr172) (1:1000) (Cell Signaling Technology), anti-SIRT1 (1:500) (Santa Cruz Biotechnology), anti-SIRT6 (1:1000) (Cell Signaling Technology), anti-SIRT3 (Cell Signaling Technology), anti-p-NF-kB (Ser536) (1:1000) (Cell Signaling Technology), anti-p16 (1:1000) (Bioworld) and anti- $\beta$-Tubulin (1:2000) (Abcam).

\section{Northern blots}

RNA was extracted from the nucleus, the cytosol or mitochondria using TRIzol reagent. $2 \mu \mathrm{g}$ nuclear RNA, $5 \mu \mathrm{g}$ cytosolic RNA and 0.5 $\mu \mathrm{g}$ mitochondrial RNA were loaded onto $6 \%$ polyacrylamide- $8 \mathrm{~mol} / \mathrm{L}$ urea gels, transferred to Amersham Hybond $N+$ membrane (GE) and hybridized with biotin-labeled RNA probes. For $h T E R C-53$ detection, biotin-labeled $h T E R C-53$ antisense RNA probe was used. For $5 S$ rRNA, biotin-labeled full length $5 S$ antisense RNA probe was used. Experiments were performed using North2South Hybridization and Detection Kit (Thermo). 


0
0
0
0
0
0
0

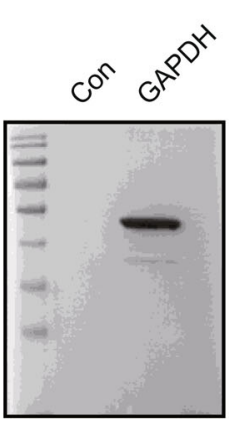

C

TSA

53

D
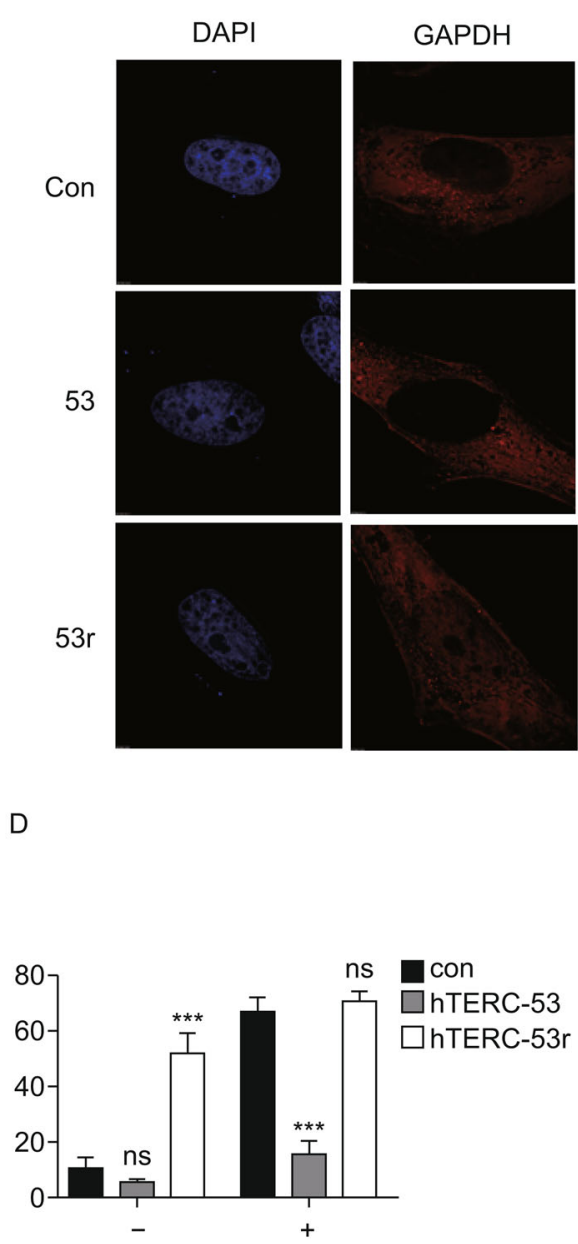

GAPDH
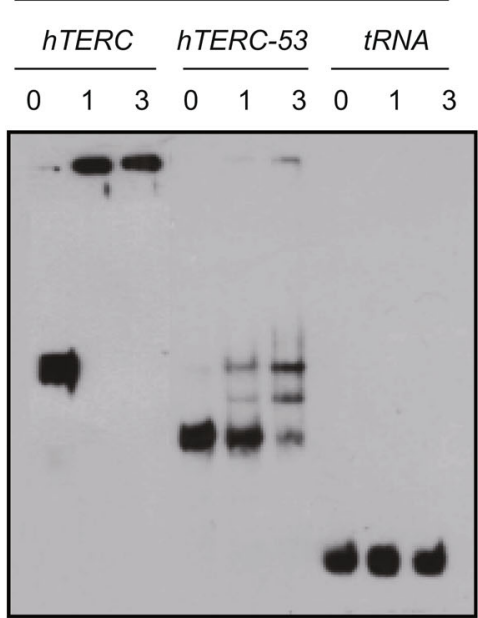

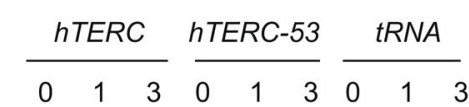

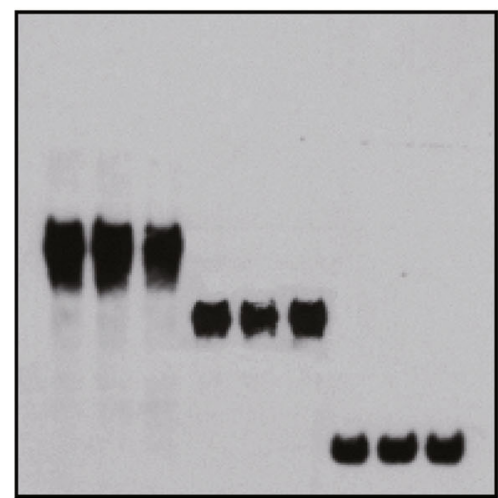

$+$

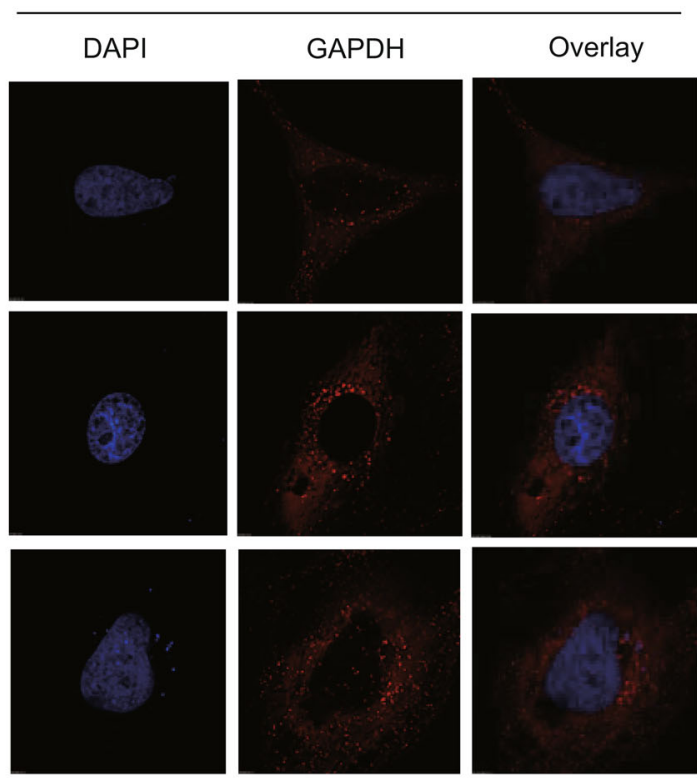

E

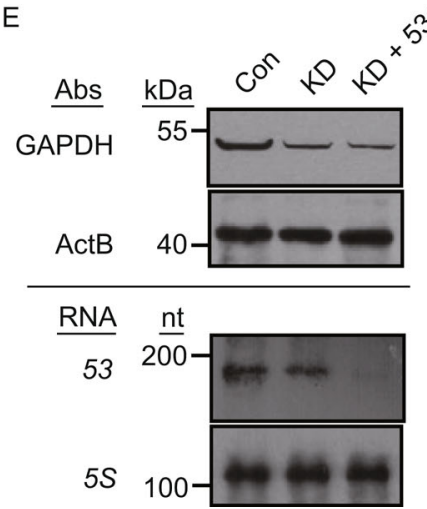

$\mathrm{F}$

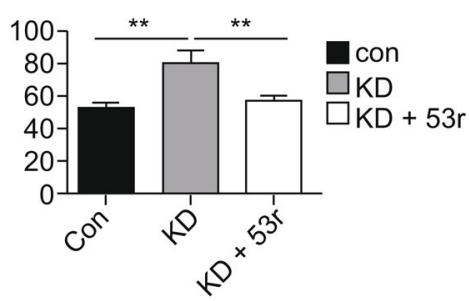


Figure 7. Exogenous expression of TERC-53 or TERC-53r affects GAPDH nuclear translocalization. (A) Coomassie staining of the purified GAPDH. (B) Gel shift assay of purified GAPDH with the indicated RNA. (C) GAPDH localization (red) in HEK293 cells overexpressing the indicated RNA, with or without TSA treatment. (D) Quantification of the number of cells with nuclear GAPDH localization in Panel (C). (E) Top panel: immunoblots of HEK293 cells with GAPDH knockdown (KD) or GAPDH knockdown combined with hTERC-53r expression (KD + 53r); bottom panel: northern blots of cytosolic hTERC-53 (53) and 5S rRNA. ( $F$ ) Percentage of SA- $\beta$-gal positive cells after $\mathrm{H}_{2} \mathrm{O}_{2}$ treatment and 3 days' recovery.

\section{Senescence-associated beta-galactosidase staining}

Senescence Cell Histochemical Staining Kit (Sigma) was used. Cells were washed twice in PBS and then fixed to plates using $1 \times$ Fixation Buffer for 6-7 min. After fixation, the cells were washed with PBS 3 times and incubated overnight at $37^{\circ} \mathrm{C}$ without $\mathrm{CO}_{2}$ in freshly prepared Staining Mixture. For induction of HEK293 cellular senescence, cells were treated with $400 \mu \mathrm{mol} / \mathrm{L}$ of $\mathrm{H}_{2} \mathrm{O}_{2}$ for $24 \mathrm{~h}$, and then grown in normal medium without $\mathrm{H}_{2} \mathrm{O}_{2}$ for 3 days before beta-Galactosidase Staining.

\section{Telomerase activity test}

Telomerase activity test was performed using TRAPEZE Telomerase Detection Kit (Millopore). Cells were lysed in CHAPS lysis buffer containing 200 units/mL RNase inhibitor. $1.5 \mu \mathrm{g}$ cell extract were used per assay. The PCR products were analyzed on a $12.5 \%$ nondenaturing PAGE and detected by SYBR Green staining.

\section{Gel shift assay}

1-2 ng biotin labeled RNA was incubated with $0,0.5$, or $1.5 \mu \mathrm{g}$ purified GAPDH in $10 \mu \mathrm{L}$ binding buffer $(150 \mathrm{mmol} / \mathrm{L} \mathrm{KCl}, 25 \mathrm{mmol} / \mathrm{L}$ Tris $\mathrm{pH} 7.4,5 \mathrm{mmol} / \mathrm{L}$ EDTA, $0.5 \mathrm{mmol} / \mathrm{L}$ DTT, $5 \%$ glycerol, 100 $\mathrm{U} / \mathrm{mL}$ RNase Inhibitor (Thermo)) at $30{ }^{\circ} \mathrm{C}$ for $20 \mathrm{~min}$. The samples were then kept on ice for $5 \mathrm{~min} ; 10 \mu \mathrm{L}$ of $2 \times$ RNA loading buffer was added to the mixture, and the samples were subjected to TBE gel electrophoresis.

\section{Fluorescent microscopy}

Hela cell lines stably expressing $h T E R C-53$, or $h T E R C-53 R$, or harboring the empty vector were transiently transfected with PQCXIP-GAPDH-mCherry for 2 days. The cells were treated with $100 \mathrm{nmol} / \mathrm{L}$ TSA (ApexBio) or DMSO for $24 \mathrm{~h}$, stained with DAPI, and then analyzed with a Zeiss confocal microscopy.

\section{MEFs culture}

MEFs were isolated as previously described (Jozefczuk et al., 2012) and cultured in DMEM containing 10\% FBS and non-essential amino acids. On day 3 , the cells were infected with adenovirus. After two days, the cells were treated with $2 \mu \mathrm{g} / \mathrm{mL}$ puromycine for $24 \mathrm{~h}$. $\beta$-Gal assay was performed on day 9 with Senescence Cell Histochemical Staining kit (Sigma).

\section{Telomere length assay}

Genomic DNA was extracted from tissues and cells with Multisource Genomic DNA miniprep kit (Axygen). For measuring telomere length, quantitative real-time PCR methods were used as previously described (Cawthon, 2009; Min et al., 2018).

\section{Animal studies}

All animal studies were performed in strict accordance with guidelines of Chinese Association for Laboratory Animal Science. Protocols were approved by the Animal Care and Use Committee at Tsinghua University.

\section{Mouse tissue TERC-53 analysis}

C57BL/6 male mice were used to analyze the level mTerc-53 in the young and the old. The young were 4 months old and the old were 10 months old. The mice were divided into pairs randomly. One pair were sacrificed each time and the fresh livers and brains were used to isolated different cellular fractions. RNA was then isolated from these fresh samples and analyzed by Northern blotting. Biotin-labeled mTerc 37 204 bp antisense RNA probe was used to detect $m$ Terc-53. 5S rRNA was used as internal control. The Northern blot results ( $n=8$ for each group) were analyzed with ImageJ software. For analysis of cytosolic TERC-53 levels in tissues, cells were isolated by treating tissues with $2 \mathrm{mg} / \mathrm{mL}$ Collagenases (Yeasen) (Type II for muscle and Type I for all the others) in regular growth medium before isolation of different cellular fractions.

\section{Adenoviral injections}

$m$-TERC53 and $m$-TERC53r expressing vectors were constructed with BLOCK-iT ${ }^{\mathrm{TM}}$ U6 RNAi Entry Vector Kit (Invitrogen) according to the supplier's instruction, and the virus were produced, amplified and purified with BLOCK-iT ${ }^{\mathrm{TM}}$ Adenoviral RNAi Expression System (Invitrogen) according to the supplier's instruction. Mice were maintained under standard housing conditions, and anaesthetized with Isoflurane $(3 \mathrm{~mL} / \mathrm{h}$ for $10 \mathrm{~min}$ to induce anaesthetization, $1.2 \mathrm{~mL} / \mathrm{h}$ to maintain the anaesthetized state). Mice were placed in the stereotaxic apparatus and a small hole was drilled at each bilateral injection location. $0.2 \mu \mathrm{L}$ virus $(0.1 \mathrm{OD})$ was injected per site using a Hamilton microsyringe $(0.02 \mu \mathrm{L} / \mathrm{min})$ into the dorsal DG using the following coordinates: anterioposterior $=-2.2 \mathrm{~mm}$ from bregma; lateral $= \pm 1.5 \mathrm{~mm}$; ventral $=2.3 \mathrm{~mm}$. The skin incision was closed carefully after adenoviral injection to minimize inflammation. Injection needles were left in place for 5 min before and after injection to ensure right location and even distribution of the virus.

\section{Behavioral experiments}

Age-matched, genotype-matched male B6 mice (middle-aged 10 months) were used for all behavioral experiments. Contextual fear conditioning (CFC) and spatial learning were performed in separate cohorts. For CFC, mice were trained 4 weeks after adenovirus (mTerc-53/mTerc-53r/con) injection. For spatial learning, mice were trained 8 weeks after AV (mTerc-53/mTerc-53r/con) injection. 


\section{Contextual fear conditioning}

The contextual fear conditioning (day 0 ) protocol entailed delivery of a single $2 \mathrm{~s}$ footshock of $0.8 \mathrm{~mA}, 180 \mathrm{~s}$ after habituation of the mouse in the training context. The mouse was taken out $10 \mathrm{~s}$ after termination of the footshock. Freezing levels were quantified over the $180 \mathrm{~s}$ habituation phase prior to the shock. On day 1 , animals were exposed to the training context (in which they did not receive a shock) for three minutes to test the $24 \mathrm{~h}$ recall. From the end of $24 \mathrm{~h}$ recall to the initial of 1 mos. recall, mice were kept in their own home cage respectively. On day 30 , animals were exposed to the training context (in which they did not receive a shock) for three minutes again, to test the 1 mos. recall. Conditioning was conducted in TSE multi CFC arena with clear front and back Plexiglas walls, black side walls, and stainless-steel bars as a floor. The arena was lit from above with a light, given back sound by a speaker, ventilated with a fan, and encased by a sound-dampening cubicle. Mouse behavior was recorded by digital video cameras mounted above the conditioning arena. For the training context (designated $A$ throughout), the fan was on, the room light was on level 500 , and the back sound was on level 1 as a white noise. Stainless-steel bars were exposed, and $1.5 \% \mathrm{HAc}$ was used as an olfactory cue. Mice were brought into the training arena in a standard housing cage. Animals were counterbalanced for order of recalls, with the second exposure occurring 29 days following the initial test. TSE multi conditioning system software was used for recording and analyzing freezing behavior.

\section{Morris water maze tasks}

The task was performed with one training phase: acquisition phase (11 days, Q4). A probe trial, in which the mice were released at the center point at the edge of the Opposite quadrant and allowed to swim for $60 \mathrm{~s}$ in the absence of the platform, was performed $24 \mathrm{~h}$ after the last trial of the acquisition phase (day 10) and twice 3 days after the first probe. The animals' trajectories were recorded with a video tracking system (EthoVision XT). The apparatus consisted of a white pool $120 \mathrm{~cm}$ in diameter and $60 \mathrm{~cm}$ deep, filled with water to a depth of $45 \mathrm{~cm}$. Four black shapes were equally spaced on the walls of the room as visible cues. Water temperature was maintained at approximately $23{ }^{\circ} \mathrm{C}$ by an automatic thermostatic system. A clear Plexiglas goal platform $9 \mathrm{~cm}$ in diameter was positioned $\sim 0.5 \mathrm{~cm}$ below the surface of the water (hidden platform), approximately 30 $\mathrm{cm}$ from the wall of the tank. Latency and frequency to reach the platform were recorded for training trials, while swim distance in quadrant were calculated for probe trials. 3 trial sessions were performed on days $0-10$, with mice released facing the wall in the center point of the edge of each quadrant except Target quadrant, in a pseudorandom order such that no single start location was used in consecutive train ( $\sim \mathrm{h}$. interest interval). Mice were allowed to swim for $60 \mathrm{~s}$, and the animals that failed to locate the platform in this time were guided to the platform and allowed to rest for $30 \mathrm{~s}$ before being removed from the tank. The latency to reach the platform was averaged for each day. Probe trials were performed on day 11 and day 14 , with mice released facing the wall in the center point of the edge of opposite quadrant. Mice were allowed to swim for $60 \mathrm{~s}$ before being removed from the tank. Mice were gently dried after each trial in both training and probes.

\section{Statistical analysis}

Statistical analysis was carried out using GraphPad Prism software. Unpaired one-tailed Student's $t$-tests were used to compare three groups or to compare preference for each quadrant in each group. To compare groups across training days for the Morris water maze, two-way repeated measures ANOVA was used. For contextual fear conditioning, behavioral data were scored by TSE multi conditioning system software. The sample size was chosen based on a previous study (McAvoy et al., 2016) and its power was validated with result analysis. Blinding was applied during the experiment. Randomization was used for selection of animals for each behavioral experiment.

\section{Immunohistological analysis}

Following anesthesia, mice were sacrificed, and heart perfusion with $4 \%$ PFA (EMS) was performed. Whole brains were rapidly harvested and post-fixed in $4 \%$ PFA at $4{ }^{\circ} \mathrm{C}$ for $24 \mathrm{~h}$. The brains were then embedded in $2 \%$ agarose. Coronal brain sections $(35 \mu \mathrm{mol} / \mathrm{L})$ were collected from vibrating microtome (Leica Inc. Germany). The slices were dried on cation coated slides at $4{ }^{\circ} \mathrm{C}$ overnight and stored without coverslips at $-20{ }^{\circ} \mathrm{C}$ until ready to use. Slides were then taken out of $-20{ }^{\circ} \mathrm{C}$ and dried at room temperature for at least 30 $\min$. All sections were antigen-retrieved with citrated acid buffer $(\mathrm{pH}$ 6.0 ) in a microwave oven, permeated with $0.5 \%$ Triton for $20 \mathrm{~min}$ after washing with PBS, and blocked with $5 \%$ GBS in PBST $(0.2 \%$ Triton) at room temperature for $2 \mathrm{~h}$. The sections were incubated with primary antibodies diluted with $5 \%$ FBS in PBST at $4{ }^{\circ} \mathrm{C}$ overnight. The next morning, the sections were washed 4 times with PBS, then incubated with secondary antibodies in the dark, washed again, and then mounted with HardSet Mounting Medium (Vectashield) and coverslips after DAPI staining. Slices were scanned with Zeiss Axio Z1 Slide scanner. The primary antibodies include rat anti-BrdU7 (1:500, abclonal), rabbit anti-NeuN (1:500, abclonal), mouse anti-Nestin (1:200, abcam) and rabbit anti-S100 $\beta$ (1:200, abcam). The secondary antibodies include goat anti-mouse IgG Alexa 488 (1:1000, Thermo), goat anti-rabbit lgG Alexa 594 (1:1000, Thermo). For BrdU incorporation, $1 \mathrm{mg} / \mathrm{g} \mathrm{BrdU}$ in $100 \mu \mathrm{L}$ of sterile PBS was i.p. injected every $24 \mathrm{~h}$ for 1 week before the histological experiments.

\section{COX and SHD histochemistry}

Slides with brain sections were taken out of $-20{ }^{\circ} \mathrm{C}$ and dried at room temperature for at least $30 \mathrm{~min}$. Reaction buffers were made fresh: for COX staining, $5 \mathrm{mmol} / \mathrm{L} \mathrm{DAB}$ and $100 \mu \mathrm{mol} / \mathrm{L}$ cytochrome $C$ were added into $0.1 \mathrm{~mL}$ PBS ( $\mathrm{pH} 7.0$ ), mixed quickly, before $2 \mu \mathrm{g}$ of bovine catalase was added; for SDH staining, $1.5 \mathrm{mmol} / \mathrm{L} \mathrm{NBT}$, $130 \mathrm{mmol} / \mathrm{L}$ sodium succinate, $0.2 \mathrm{mmol} / \mathrm{L} \mathrm{PMS}$, and $1 \mathrm{mmol} / \mathrm{L}$ sodium azide were added into $0.1 \mathrm{~mL}$ PBS $(\mathrm{pH} 7.0)$, and mixed quickly in the dark. Slides were incubated with the buffers for $40 \mathrm{~min}$ at $37{ }^{\circ} \mathrm{C}$, washed, dehydrated with gradient ethanol, mounted with Hardset Mounting Medium, and scanned with Zeiss Axio Z1 Slide scanner. 
Differentially expression analysis and gene ontology annotations

Tophat (Trapnell et al., 2012) was used to map cleaned RNA sequencing reads to hg19 genome, and GFOLD was then used for differentially expression analysis (Feng et al., 2012). To identify significantly differentially expressed genes, each candidate gene needs to meet two criteria below: i. GFOLD $>1$ or GFOLD $<-1$; ii. $q-$ value $<0.05$. An $R$ package topGO was used for Gene Ontology enrichment analysis. Hypergeometric test was used to measure the significance of GO term enrichments.

\section{ACKNOWLEDGMENTS}

We thank Dr. Zhenyu Ju for providing us the $\operatorname{terc}^{-/+}$mice, Dr. Zengcai Guo for the help on histochemical studies, and Dr. Lei Liu for helpful discussion. This research was supported by the Priority Research Program of the Ministry of Science and Technology of the People's Republic of China 2017YFA0504600, National Natural Science Foundation of the People's Republic of China grant 31371439, 91649103, and Ministry of Education of the People's Republic of China 1000 Talents Youth program.

\section{AUTHOR CONTRIBUTIONS}

Q.Z. performed the Northern blotting, and the senescence assays. P.L. and F.D. performed the histochemical assays. G.G. and Y.C. performed the mouse behavioral experiments. J.Y. analyzed the RNAseq data. P.W., L.X., J.H. and X.L. performed most of the immunoblotting. T.T., J.C., Z.L., J.G. and G.W. conceived the ideas, designed the experiments and wrote the paper.

\section{COMPLIANCE WITH ETHICS GUIDELINES}

Qian Zheng, Peipei Liu, Ge Gao, Jiapei Yuan, Pengfeng Wang, Jinliang Huang, Leiming Xie, Xinping Lu, Fan Di, Tanjun Tong, Jun Chen, Zhi Lu, Jisong Guan, and Geng Wang declare that they have no conflict of interest.

All institutional and national guidelines for the care and use of laboratory animals were followed. This article does not contain any studies with human subjects performed by any of the authors.

\section{OPEN ACCESS}

This article is distributed under the terms of the Creative Commons Attribution 4.0 International License (http://creativecommons.org/ licenses/by/4.0/), which permits unrestricted use, distribution, and reproduction in any medium, provided you give appropriate credit to the original author(s) and the source, provide a link to the Creative Commons license, and indicate if changes were made.

\section{REFERENCES}

Acquati F, Morelli C, Cinquetti R, Bianchi MG, Porrini D, Varesco L, Gismondi V, Rocchetti R, Talevi S, Possati L et al (2001) Cloning and characterization of a senescence inducing and class II tumor suppressor gene in ovarian carcinoma at chromosome region 6q27. Oncogene 20:980-988
Alfonzo JD, Soll D (2009) Mitochondrial tRNA import-the challenge to understand has just begun. Biol Chem 390:717-722

Azam S, Jouvet N, Jilani A, Vongsamphanh R, Yang X, Yang S, Ramotar D (2008) Human glyceraldehyde-3-phosphate dehydrogenase plays a direct role in reactivating oxidized forms of the DNA repair enzyme APE1. J Biol Chem 283:30632-30641

Bernardes de Jesus B, Blasco MA (2013) Telomerase at the intersection of cancer and aging. Trends Genet 29:513-520

Bishop NA, Lu T, Yankner BA (2010) Neural mechanisms of ageing and cognitive decline. Nature 464:529-535

Blasco MA, Lee HW, Hande MP, Samper E, Lansdorp PM, DePinho RA, Greider CW (1997) Telomere shortening and tumor formation by mouse cells lacking telomerase RNA. Cell 91:25-34

Cawthon RM (2009) Telomere length measurement by a novel monochrome multiplex quantitative PCR method. Nucleic Acids Res 37:e21

Chang C, Su H, Zhang D, Wang Y, Shen Q, Liu B, Huang R, Zhou T, Peng C, Wong CC et al (2015) AMPK-dependent phosphorylation of GAPDH triggers Sirt1 activation and is necessary for autophagy upon glucose starvation. Mol Cell 60:930-940

Chang DD, Clayton DA (1989) Mouse RNAase MRP RNA is encoded by a nuclear gene and contains a decamer sequence complementary to a conserved region of mitochondrial RNA substrate. Cell 56:131-139

Chen HW, Rainey RN, Balatoni CE, Dawson DW, Troke JJ, Wasiak S, Hong JS, McBride HM, Koehler CM, Teitell MA et al (2006) Mammalian polynucleotide phosphorylase is an intermembrane space RNase that maintains mitochondrial homeostasis. Mol Cell Biol 26:8475-8487

Cheng Y, Liu P, Zheng Q, Gao G, Yuan J, Wang P, Huang J, Xie L, Lu X, Tong T et al (2018) Mitochondrial trafficking and processing of telomerase RNA TERC. Cell Rep 24:2589-2595

Chuang DM, Ishitani R (1996) A role for GAPDH in apoptosis and neurodegeneration. Nat Med 2:609-610

Coates PJ, Jamieson DJ, Smart K, Prescott AR, Hall PA (1997) The prohibitin family of mitochondrial proteins regulate replicative lifespan. Curr Biol 7:607-610

Feng J, Meyer CA, Wang Q, Liu JS, Shirley Liu X, Zhang Y (2012) GFOLD: a generalized fold change for ranking differentially expressed genes from RNA-seq data. Bioinformatics 28:2782-2788

Gall JG (1990) Telomerase RNA: tying up the loose ends. Nature 344:108-109

Gottlieb RA, Bernstein D (2016) Mitochondrial remodeling: rearranging, recycling, and reprogramming. Cell Calcium 60:88-101

Guha M, Avadhani NG (2013) Mitochondrial retrograde signaling at the crossroads of tumor bioenergetics, genetics and epigenetics. Mitochondrion 13:577-591

Hachiya N, Alam R, Sakasegawa Y, Sakaguchi M, Mihara K, Omura $T$ (1993) A mitochondrial import factor purified from rat liver cytosol is an ATP-dependent conformational modulator for precursor proteins. EMBO J 12:1579-1586

Hara MR, Agrawal N, Kim SF, Cascio MB, Fujimuro M, Ozeki Y, Takahashi M, Cheah JH, Tankou SK, Hester LD et al (2005) S-nitrosylated GAPDH initiates apoptotic cell death by nuclear translocation following Siah1 binding. Nat Cell Biol 7:665-674

Jaskelioff M, Muller FL, Paik JH, Thomas E, Jiang S, Adams AC, Sahin E, Kost-Alimova M, Protopopov A, Cadinanos J et al (2011) 
Telomerase reactivation reverses tissue degeneration in aged telomerase-deficient mice. Nature 469:102-106

Jozefczuk J, Drews K, Adjaye J (2012) Preparation of mouse embryonic fibroblast cells suitable for culturing human embryonic and induced pluripotent stem cells. J Vis Exp. https://doi.org/10. 3791/3854

Kotiadis VN, Duchen MR, Osellame LD (2014) Mitochondrial quality control and communications with the nucleus are important in maintaining mitochondrial function and cell health. Biochim Biophys Acta 1840:1254-1265

Li N, Li Q, Cao X, Zhao G, Xue L, Tong T (2011) The tumor suppressor p33ING1b upregulates p16INK4a expression and induces cellular senescence. FEBS Lett 585:3106-3112

Liu P, Huang J, Zheng Q, Xie L, Lu X, Jin J, Wang G (2017) Mammalian mitochondrial RNAs are degraded in the mitochondrial intermembrane space by RNASET2. Protein Cell 8:735-749

Lopez-Otin C, Blasco MA, Partridge L, Serrano M, Kroemer G (2013) The hallmarks of aging. Cell 153:1194-1217

Lopez-Otin C, Galluzzi L, Freije JM, Madeo F, Kroemer G (2016) Metabolic control of longevity. Cell 166:802-821

Lu T, Pan Y, Kao SY, Li C, Kohane I, Chan J, Yankner BA (2004) Gene regulation and DNA damage in the ageing human brain. Nature 429:883-891

McAvoy KM, Scobie KN, Berger S, Russo C, Guo N, Decharatanachart $\mathrm{P}$, Vega-Ramirez $\mathrm{H}$, Miake-Lye S, Whalen $\mathrm{M}$, Nelson $\mathrm{M}$ et al (2016) Modulating neuronal competition dynamics in the dentate gyrus to rejuvenate aging memory circuits. Neuron 91:1356-1373

Mercer TR, Neph S, Dinger ME, Crawford J, Smith MA, Shearwood AM, Haugen E, Bracken CP, Rackham O, Stamatoyannopoulos JA et al (2011) The human mitochondrial transcriptome. Cell 146:645-658

Min B, Park M, Jeon K, Park JS, Seo H, Jeong S, Kang YK (2018) Age-associated bimodal transcriptional drift reduces intergenic disparities in transcription. Aging 10:789-807

Nagy E, Henics T, Eckert M, Miseta A, Lightowlers RN, Kellermayer $M(2000)$ Identification of the NAD(+)-binding fold of glyceraldehyde-3-phosphate dehydrogenase as a novel RNA-binding domain. Biochem Biophys Res Commun 275:253-260

Nicholls C, Pinto AR, Li H, Li L, Wang L, Simpson R, Liu JP (2012) Glyceraldehyde-3-phosphate dehydrogenase (GAPDH) induces cancer cell senescence by interacting with telomerase RNA component. Proc Natl Acad Sci USA 109:13308-13313

Phadke M, Krynetskaia N, Mishra A, Krynetskiy E (2011) Accelerated cellular senescence phenotype of GAPDH-depleted human lung carcinoma cells. Biochem Biophys Res Commun 411:409415

Reczek CR, Chandel NS (2015) ROS-dependent signal transduction. Curr Opin Cell Biol 33:8-13

Rudolph KL, Chang S, Lee HW, Blasco M, Gottlieb GJ, Greider C, DePinho RA (1999) Longevity, stress response, and cancer in aging telomerase-deficient mice. Cell 96:701-712
Sarkar D, Leszczyniecka M, Kang DC, Lebedeva IV, Valerie K, Dhar S, Pandita TK, Fisher PB (2003) Down-regulation of Myc as a potential target for growth arrest induced by human polynucleotide phosphorylase (hPNPaseold-35) in human melanoma cells. J Biol Chem 278:24542-24551

Sato R, Arai-Ichinoi N, Kikuchi A, Matsuhashi T, Numata-Uematsu Y, Uematsu M, Fujii Y, Murayama K, Ohtake A, Abe T et al (2017) Novel biallelic mutations in the PNPT1 gene encoding a mitochondrial-RNA-import protein PNPase cause delayed myelination. Clin Genet. https://doi.org/10.3791/3854

Sawa A, Khan AA, Hester LD, Snyder SH (1997) Glyceraldehyde-3phosphate dehydrogenase: nuclear translocation participates in neuronal and nonneuronal cell death. Proc Natl Acad Sci USA 94:11669-11674

Schulz AM, Haynes CM (2015) UPR(mt)-mediated cytoprotection and organismal aging. Biochim Biophys Acta 1847:1448-1456

Sen N, Hara MR, Kornberg MD, Cascio MB, Bae BI, Shahani N, Thomas B, Dawson TM, Dawson VL, Snyder SH et al (2008) Nitric oxide-induced nuclear GAPDH activates p300/CBP and mediates apoptosis. Nat Cell Biol 10:866-873

Sullivan LB, Chandel NS (2014) Mitochondrial reactive oxygen species and cancer. Cancer Metab 2:17

Sun N, Youle RJ, Finkel T (2016) The mitochondrial basis of aging. Mol Cell 61:654-666

Trapnell C, Roberts A, Goff L, Pertea G, Kim D, Kelley DR, Pimentel H, Salzberg SL, Rinn JL, Pachter L (2012) Differential gene and transcript expression analysis of RNA-seq experiments with TopHat and Cufflinks. Nat Protoc 7:562-578

Vedrenne V, Gowher A, De Lonlay P, Nitschke P, Serre V, Boddaert $\mathrm{N}$, Altuzarra C, Mager-Heckel AM, Chretien F, Entelis $\mathrm{N}$ et al (2012) Mutation in PNPT1, which encodes a polyribonucleotide nucleotidyltransferase, impairs RNA import into mitochondria and causes respiratory-chain deficiency. Am J Hum Genet 91:912918

von Ameln S, Wang G, Boulouiz R, Rutherford MA, Smith GM, Li Y, Pogoda HM, Nurnberg G, Stiller B, Volk AE et al (2012) A mutation in PNPT1, encoding mitochondrial-RNA-import protein PNPase, causes hereditary hearing loss. Am J Hum Genet 91:919-927

Wallace DC (2012) Mitochondria and cancer. Nature reviews. Cancer 12:685-698

Wang G, Chen HW, Oktay Y, Zhang J, Allen EL, Smith GM, Fan KC, Hong JS, French SW, McCaffery JM et al (2010) PNPASE regulates RNA import into mitochondria. Cell 142:456-467

Yee C, Yang W, Hekimi S (2014) The intrinsic apoptosis pathway mediates the pro-longevity response to mitochondrial ROS in $C$. elegans. Cell 157:897-909

Zhang X, Zuo X, Yang B, Li Z, Xue Y, Zhou Y, Huang J, Zhao X, Zhou J, Yan $Y$ et al (2014) MicroRNA directly enhances mitochondrial translation during muscle differentiation. Cell 158:607-619 